\title{
Evolución geológica del sureste mexicano desde el Mesozoico al presente en el contexto regional del Golfo de México
}

\author{
Ricardo José Padilla y Sánchez \\ Universidad Nacional Autónoma de México, Facultad de Ingeniería, División en Ciencias de la Tierra \\ Cd. Universitaria, México D.F. 04510 \\ rjpadilla@dictfi.unam.mx
}

\section{Resumen}

La evolución geológica del sureste mexicano es analizada en el contexto regional del Golfo de México que inicia su apertura con la fragmentación y dispersión de la Pangea. La sedimentación en esta depresión empieza con el depósito de lechos rojos continentales durante el Triásico Tardío y el Jurásico Temprano, después de lo cual, durante el Calloviano, se produce una invasión por aguas marinas provenientes del Pacífico que cubren una extensa zona con poca circulación, poco tirante de agua y alta evaporación, condiciones que favorecen el depósito de grandes volúmenes de sal en la zona central de la cuenca. Desde el Jurásico Tardío hasta el Cretácico Tardío la sedimentación estuvo dominada por carbonatos, cambiando a clásticos a principios del Paleógeno a causa de la Orogenia Laramide, evento tectónico que formó la Sierra Madre Oriental. Durante el resto del Paleógeno la sedimentación clástica se fue alojando en grandes depocentros formados en el antepaís de la Sierra Madre Oriental y en las porciones sur y suroccidental del Golfo de México, en donde el Macizo de Chiapas aportó un gran volumen de sedimentos, mientras que sobre el Bloque Yucatán continuaba el depósito de carbonatos de plataforma somera. En el Mioceno medio, durante el Serravaliano, la compresión derivada del movimiento lateral del Bloque Chortis y de la subducción de la Placa de Cocos contra la terminación meridional de la Placa de Norteamérica, formó los pliegues y fallas de la cadena de Chiapas-Reforma-Akal sobre un décollement al nivel de la sal calloviana; posteriormente estas estructuras se bascularon hacia el NNW cuando la sal se movilizó hacia el norte. El cambio de posición de la masa de sal generó nuevos depocentros y minicuencas, controlados por fallas con vergencia hacia las partes más profundas del Golfo de México y por fallas antitéticas regionales, que limitan las Cuencas del Sureste. El movimiento gravitacional de los depósitos cenozoicos causó finalmente inversión tectónica en las cuencas neógenas, siendo esta más evidente en la Cuenca de Macuspana.

Palabras clave: Alto de Anegada, Cadena Plegada Reforma-Campeche, Cuenca de Comalcalco, Cuenca de Macuspana, Cuenca de Veracruz, Cuenca Salina del Istmo, Cuencas del Sureste, evolución geológica del Golfo de México, Falla Transformante TamaulipasOaxaca, Franja de Chiapas-Reforma-Akal, Horst de la Faja de Oro, Horst de Reforma-Akal, Lineamiento de Boquillas-Sabinas, Lineamiento de Sierra Mojada-China, Macizo de Chiapas, Pilar de Akal, Sierra de Chiapas, Sierra de Zongolica, Sierra Madre Oriental, tectónica del Golfo de México.

\footnotetext{
Abstract

The geologic evolution of southeastern Mexico is analyzed in the regional context of the Gulf of Mexico, which starts it opening with the fragmentation and spreading of Pangea. The sedimentary record in this depression begins with the deposit of continental red beds during the Late Triassic and Early Jurassic, after which, during the Callovian, sea-waters from the Pacific invaded an extense area; low circulation and high evaporation of these waters allowed the deposition of large volumes of salt in the central part of the basin. From Late Jurassic to Late Cretaceous, carbonate deposition prevailed, changing to clastic at the beginning of the Paleogene, when the Laramide Orogeny formed the folds and faults of the Sierra Madre Oriental. During the rest of the Paleogene clastic sedimentation was deposited in large depocenters generated in the foreland of the Sierra Madre Oriental, and in the southern and southwestern parts of the Golf of Mexico, where the Chiapas Massif produced large volumes of sediments, whereas in the Yucatan Block the deposition of shallow water carbonates continued. In the Middle Miocene, during the Serravalian, compressive stresses resulting from the lateral movement of the Chortis Block and the subduction of the Cocos Plate, against the southern end of the North American Plate, formed the folds and faults of the Chiapas-Reforma-Akal belt over a décollement at the level of the Callovian salt; later, these structures were
} 
tilted to the NNW when the salt was mobilized northward. The change of location of this mass of salt caused new depocenters and minibasins, comptrolled by faults with a vergence toward the deepest parts of the Gulf of Mexico, and by regional antithetic faults, which limit the Cuencas del Sureste. The gravitational movement of the Cenozoic deposits, finally caused tectonic inversion in the neogene basins, from which the most evident is the Macuspana Basin.

Key words: Anegada High, Reforma-Campeche Folded Belt, Comalcalco Basin, Macuspana Basin, Veracruz Basin, Salina del Istmo Basin, Cuencas del Sureste, Gulf of Mexico, Gulf of Mexico geologic evolution, Tamaulipas-Oaxaca Transform Fault, ChiapasReforma-Akal Belt, Goleen Lane Horst, Reforma-Akal Horst, Boquillas-Sabinas Lineament, Sierra Mojada-China Lineament, Chiapas Massif, Akal High, Sierra de Chiapas, Sierra de Zongolica, Sierra Madre Oriental, Gulf of Mexico tectonics.

\section{Introducción}

El sureste mexicano se refiere aquí a la zona comprendida al oriente del Istmo de Tehuantepec y al occidente de la Península de Yucatán, incluyendo parte del área marina meridional del Golfo de México, aproximadamente entre las coordenadas geográficas $91^{\circ}$ a $95^{\circ}$ de longitud al oeste de Greenwich y de $16^{\circ}$ a $20^{\circ}$ de latitud norte. El área de este estudio incluye las Cuencas del Sureste (ComalcalcoSalina del Istmo y Macuspana), así como la cadena plegada de la Sierra de Chiapas- Reforma-Akal, de la que su tramo Reforma-Akal se conoce solamente por datos del subsuelo (Figura 1).

Desde el punto de vista geológico el sureste mexicano es una de las áreas más complejas de Norteamérica. Esta complejidad se debe a que los movimientos de las placas tectónicas Norteamericana, del Caribe y de Cocos, convergen en esta región desde el Oligoceno Tardío (MoránZenteno et al., 2000); la Placa Norteamericana tiene un movimiento relativo hacia el oeste respecto a la del Caribe, mientras que la de Cocos se mueve hacia el noroeste en dirección hacia las dos primeras. Las estructuras resultantes de esta actividad tectónica durante el Mesozoico y Cenozoico presentan tendencias estructurales diversas, así como también edades de deformación diferentes. Por ejemplo, la Sierra de Chiapas esta constituida por rocas carbonatadas que varían en edad desde el Jurásico tardío hasta el Paleógeno, mismas que fueron deformadas durante el Mioceno Tardío dando lugar a un conjunto de pliegues asimétricos orientados NW-SE y con una vergencia general al NE. Después de este evento orogénico, como resultado del desalojo de grandes volúmenes de sal y arcilla, se formaron cuencas extensionales cuya dirección de extensión está orientada casi a $90^{\circ}$ de los ejes de los pliegues de la cadena. Sin embargo, la Sierra de Chiapas es una cadena plegada y cabalgada atípica que no presenta en su frente tectónico una cuenca de antepaís, como es el caso de las cadenas de la Sierra de Zongolica y de la Sierra Madre Oriental, del borde occidental del Golfo de México.

El objetivo de este trabajo es integrar la historia tectónica, estructural y sedimentaria del sureste mexicano con la evolución regional del Golfo de México. Los datos presentados más adelante en las secciones geológicas son el resultado de la interpretación de líneas sísmicas que realizó el que escribe en numerosos trabajos efectuados durante varios años para PEMEX. Los datos de las secciones y de los pozos fueron dibujados a una escala pequeña por razones de confidencialidad, pero los mapas presentados en este artículo fueron derivados de la versión digital del Mapa Tectónico de México (Padilla y Sánchez et al., 1995). En la Figura 2 se muestra una síntesis de los eventos tectónicos principales en el sureste mexicano.

En el desarrollo de este trabajo primeramente se exponen los datos que se conocen acerca del basamento premesozoico, en la región que hoy ocupa el Golfo de México. Posteriormente se analiza el proceso de rifting que dio origen a la apertura del mismo y cual fue el papel que jugó el movimiento del Bloque Yucatán, todo esto apoyado en mapas paleogeográficos regionales. Finalmente se discute la evolución tectónica y sedimentaria del Golfo de México desde el Mesozoico hasta el Cenozoico, con énfasis en el sureste mexicano.

Es necesario aclarar que en este trabajo se utilizan pocos nombres de formaciones porque se prefiere utilizar las facies generadas y el tiempo en el que ocurrió el depósito, pero como algunos nombres formacionales son muy conocidos (i.e. Lutita Méndez), se mencionan ocasionalmente en el trabajo. En la Figura 3 se muestra de forma esquemática la litoestratigrafía del sureste mexicano.

\section{Trabajos Previos}

Los primeros estudios del sureste de México fueron publicados en la primera mitad del siglo XX por Böse (1905, 1906), Villarello (1909), Burckhardt (1930), Gibson (1936a, 1936b), Alvarez (1949, 1951), Viniegra (1950) y Oñate (1950). Posteriormente, Castillo-Tejero (1955) y Contreras (1959), sintetizaron la estratigrafía y la geología histórica del área.

La existencia de grandes yacimientos de petróleo es el motivo por el cual el sureste mexicano ha sido estudiado principalmente con datos sísmicos $2 \mathrm{D}$ y $3 \mathrm{D}$, así como con la perforación de cientos de pozos. Los datos sobre la geología superficial y del subsuelo han sido publicados por geólogos de PEMEX (Alvarez, 1949; Viniegra, 1950, 1971,1981, Ricoy, 1989; Meneses, 1991; García-Molina,1994), quienes ya mencionaban la existencia de las Cuencas Terciarias del sureste mexicano, aunque se desconoce quien las denominó así originalmente. 


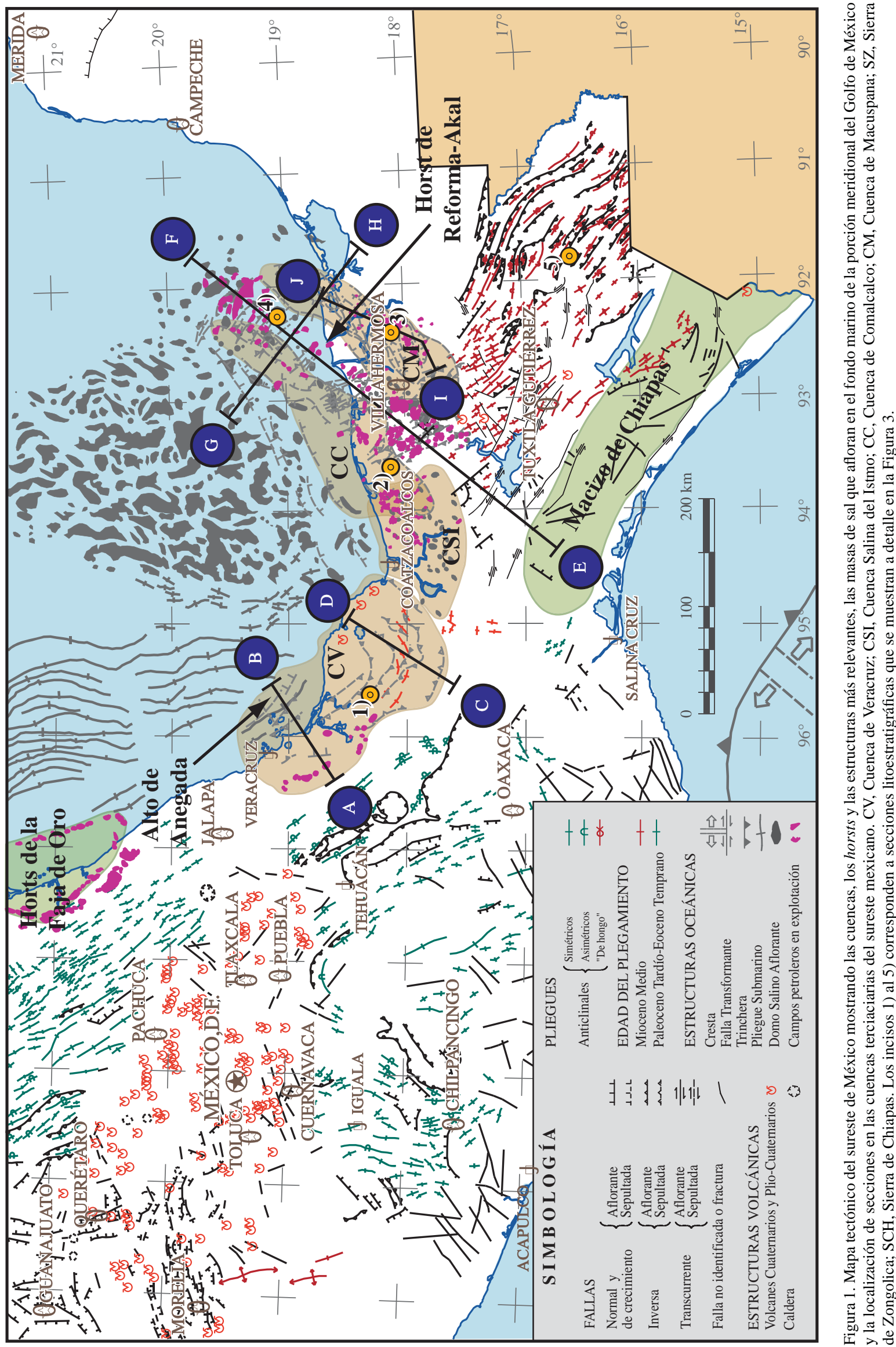




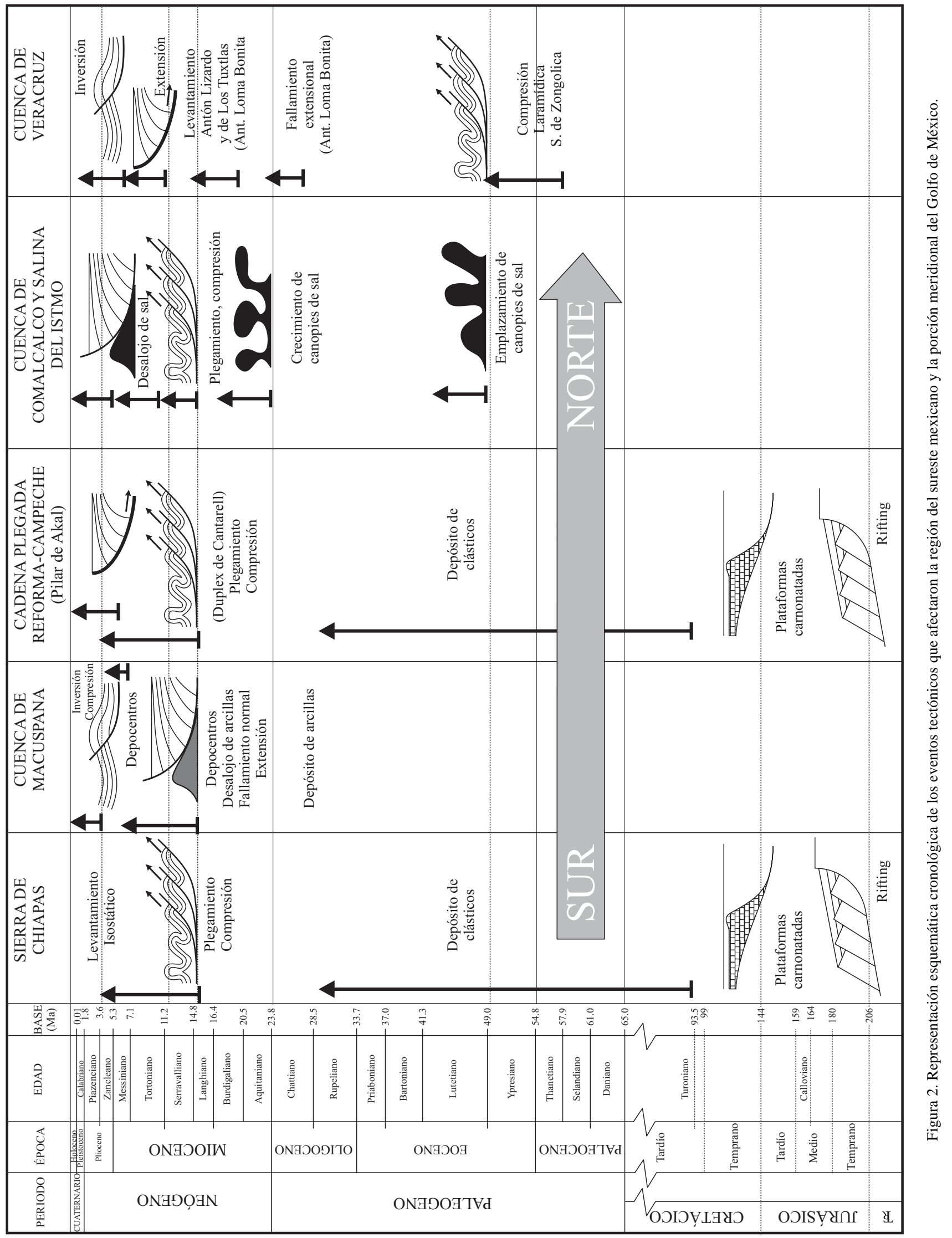



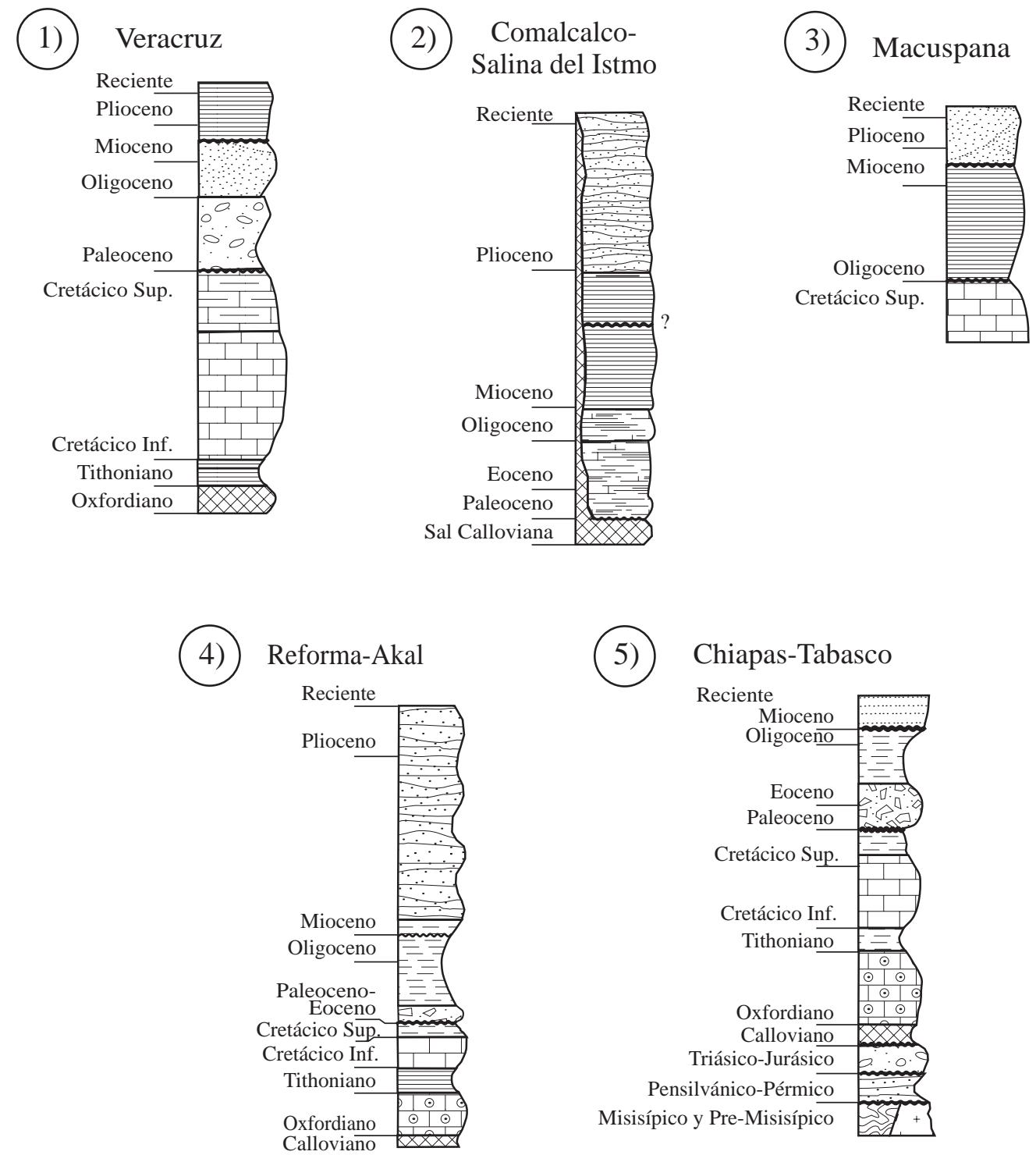

Figura 3. Litoestratigrafía regional del sureste mexicano en la porción meridional del Golfo de México.

Sánchez-Montes de Oca (1969, 1980), Ingeniero Geólogo de PEMEX realizó uno de los trabajos principales sobre la geología superficial de la Sierra de Chiapas. Este autor propuso dos edades de deformación para las estructuras de la Sierra de Chiapas, el Ciclo Chiapaneco (Mioceno tardío) y el Ciclo Cascadiano del Plioceno. Otros autores agregaron posteriormente datos estratigráficos y cartográficos valiosos (López-Vega, 1980; Quezada-Muñetón, 1987; Santiago-Acevedo y Mejía-Dautt, 1980). Hoy se sabe que las principales rocas almacén son areniscas del Mioceno, calizas del Kimmeridgiano y del Cretácico SuperiorPaleoceno, y que las rocas fuente de los hidrocarburos son principalmente las lutitas del Tithoniano (Holguín, 1985; González y Holguín, 1992).

En la década de los ochenta del siglo pasado, geólogos franceses contribuyeron al conocimiento tectónico y estratigráfico a través de estudios de geología superficial (Carfantan, 1986; Michaud, 1987), identificando algunas etapas de la apertura del Golfo de México, desde el Permotriásico hasta el Calloviano. Otros autores enfocaron sus estudios al sistema centroamericano de fallas de desplazamiento lateral de Motagua-Polochic, mismo que trataron de extender hasta la Sierra de Chiapas (Burkart, 1983; Burkart et al., 1987; Burkart y Scotese, 1990; Meneses, 1991).

A principios de este siglo se publicó un número especial de la American Association of Petroleum Geologists, que incluye muy buenos trabajos sobre aspectos tectónicos, sedimentarios y de sistemas petroleros relativos a las cuencas del borde occidental del Golfo de México (Bartolini et al., 2001), pero muy poco en lo relacionado con el sureste mexicano (Angeles-Aquino y Cantú-Chapa, 2001; Martínez- 
Castillo, 2001; Williams-Rojas y Hurley, 2001).

Para comprender mejor la evolución geológica del sureste mexicano es conveniente considerar el marco tectónico regional del Golfo de México y del Caribe. Muchos trabajos se han publicado en el contexto regional incluyendo reconstrucciones de tectónica de placas, de los cuales destacan los trabajos de Pindell (1985, 1993), Winker y Buffler (1988), Ross y Scotese (1988), Stephan et al. (1990) y Salvador (1987, 1991a). Este último sintetiza de manera sobresaliente la mayoría de los trabajos que se habían publicado hasta entonces, aunque se refiere poco al sureste mexicano porque entonces se conocían poco los datos de Pemex.

Recientemente otros autores han efectuado estudios sobre los yacimientos neógenos en las cuencas de Macuspana (Ambrose, et al., 2003) y de Veracruz (Jennette, et al., 2003), pero aún no se ha publicado uno que integre la geología del sureste mexicano.

\section{Basamento Pre-Mesozoico}

El conocimiento que se tiene del basamento preMesozoico en el área del Golfo de México y sus alrededores es escaso y está basado en unos cuantos afloramientos que en su mayoría se encuentran en localidades mexicanas (Cd. Victoria, Aramberri, Huayacocotla, Oaxaca, La Mixtequita). Los otros afloramientos más cercanos son los del área de Llano y Marathón en Texas y los de la zona de las Montañas Ouachita y Apalaches del sur de Estados Unidos (Figura 4).

En el Golfo de México meridional el basamento aflora en el Macizo de Chiapas, al sur de la Sierra de Chiapas, en donde está constituído por un complejo de rocas metasedimentarias del Precámbrico Superior al Paleozoico Inferior (Sedlock et al., 1993), intrusionadas por granitos, granodioritas y tonalitas datadas con métodos radiométricos de K-Ar y de Rb-Sr como del Permotriásico (Pantoja et

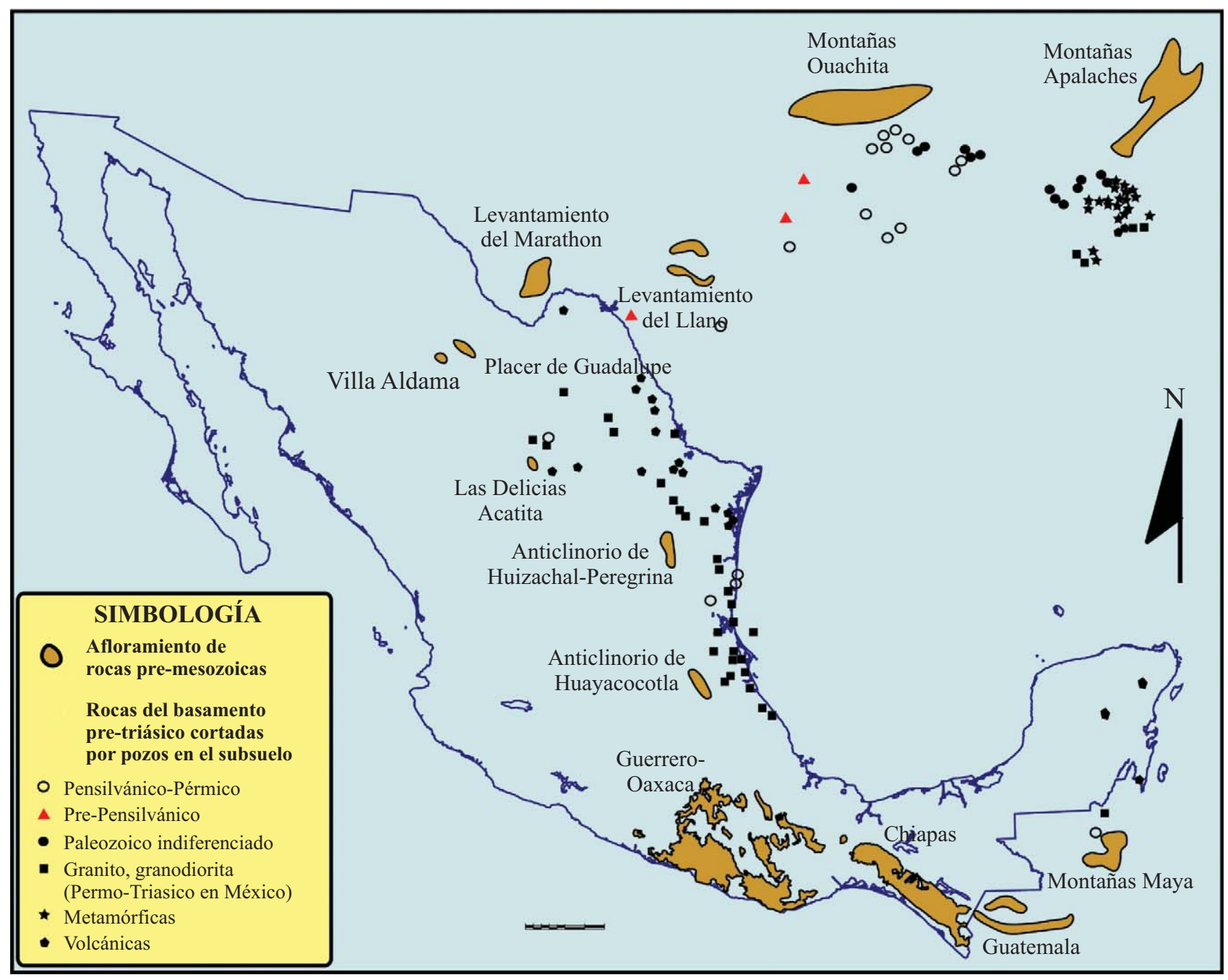

Figura 4. Localidades en donde aflora el basamento pre-mesozoico y pozos que lo han perforado en el subsuelo de áreas circunvecinas al Golfo de México. (Modificada de Woods et al., 1991). 
al., 1974; López-Infanzón, 1986; Pacheco y Barba, 1986). Pero es importante aclarar que no todas las rocas intrusivas en el Macizo de Chiapas son de esa edad, pues Burkart $e t$ al. (1987) dataron algunas muestras como del Cretácico Superior.

En el suroriente de Chiapas (Chicomuselo), norte de Guatemala (Tactic) y occidente de Belice (San Miguel Ixtatán), rocas sedimentarias paleozoicas descansan discordantes sobre la secuencia de rocas metasedimentarias mencionadas. La parte inferior de la sección paleozoica consiste de areniscas de grano grueso y limolitas, con algunos horizontes ocasionales de conglomerados y algunas lutitas que localmente muestran metamorfismo de bajo grado. Recientemente se determinaron en el oeste de Villaflores, Chiapas, edades de 252-254 Ma, con circones, por el método U-Pb (SHRIMP), así como una edad de $~ 243$ Ma por el método de ${ }^{40} \mathrm{Ar} /{ }^{39} \mathrm{Ar}$ en hornblendas para el levantamiento y enfriamiento del Macizo de Chiapas (Hiller et al., 2004). En Chiapas y en Guatemala se han reportado espesores de 1,000 a 3,000 m para esta secuencia, misma a la que se ha asignado una edad del Pensilvánico con base en su posición estratigráfica. Sobre la sección inferior descrita, descansa concordante una secuencia de lutitas y limolitas, con algunas areniscas, y ocasionalmente, capas carbonatadas generalmente discontinuas, mismas que aumentan hacia la cima, a la vez que disminuyen las areniscas. El espesor de esta sección varía de 500 a 1,300 m y su edad ha sido determinada con fusulínidos colectados en las capas de caliza como del Pensilvánico Superior al Pérmico Inferior (Hernández-García, 1973). La parte superior de la sección paleozoica en Chiapas y Guatemala está compuesta por calizas de estratificación gruesa a masiva y está ausente en las Montañas Maya de Belice. En Guatemala su espesor varía de 500 a 1,000 m, pero puede alcanzar cerca de 2,000 $\mathrm{m}$ en Chiapas. Se le ha asignado una edad del Pérmico Inferior a Medio con base a los fusulínidos que contiene (especies Schuagerina, géneros Eoverbeekina, Stafella y Nankinella) (Hernández-García, ibid).

No se incluye en este trabajo una descripción de las rocas del Complejo Oaxaqueño o del Acatlán, por ser irrelevantes para el objetivo del mismo.

\section{Rift Triásico Superior-Jurásico Medio, apertura del Golfo de México y el desplaza-miento del Bloque de Yucatán}

La fragmentación y separación inicial de la Pangea en el área que hoy ocupa el Golfo de México está evidenciada por la presencia de lechos rojos que fueron depositados en depresiones continentales cuya geometría estuvo controlada por grabenes estrechos con direcciones aproximadamente paralelas a la actual línea de costa (Salvador, 1991c). Al igual que en el caso del basamento premesozoico, alrededor del Golfo de México existen sólo algunas localidades en donde afloran lechos rojos, principalmente a lo largo de la Sierra Madre Oriental, en las áreas de Galeana, Nuevo León, Huizachal, Tamaulipas (Padilla y Sánchez, 1982), Huayacocotla y sur de Tehuacán (Cañón de Tomellín), Puebla (Ramírez-Ramírez, 1984; Salvador, 1991b), Cerro Pelón, Veracruz, y en la Sierra Monoclinal, ubicada entre el Macizo y la Sierra de Chiapas, Chiapas (Meneses, 2001). En la Figura 5 se muestra de forma esquemática, la ubicación estimada de los grabenes.

Además de las localidades mencionadas, en los alrededores del Golfo de México se conocen rocas equivalentes a esos lechos rojos solamente en el subsuelo de Chiapas, en donde fueron penetradas por los pozos Sauzal-1, Raudales1, Soyaló-1, San Cristóbal-1, El Retiro-1 y Nazareth-51 (Meneses, ibid). También se tienen datos sobre rocas equivalentes en el subsuelo de la parte norte del Golfo de México en los estados de Texas, Louisiana, Missouri, Georgia y norte de Florida, en los Estados Unidos de América, en donde se les ha identificado genéricamente como la Formación Eagle Mills (Shearer, 1938; Weeks, 1938).

La posición estratigráfica de los lechos rojos en el Golfo de México meridional sugiere que su edad de depósito varía desde el Triásico Tardío hasta después del Calloviano, porque se les ha descrito abajo, lateralmente equivalentes y arriba de la sal calloviana. Esto probablemente se debió a un depósito contemporáneo de la sal en la cuenca, mientras que en los bordes de la misma se depositaban lechos rojos.

El proceso tectónico de separación de la Pangea prevaleció hasta el final del Jurásico Medio, pero quizá alcanzó

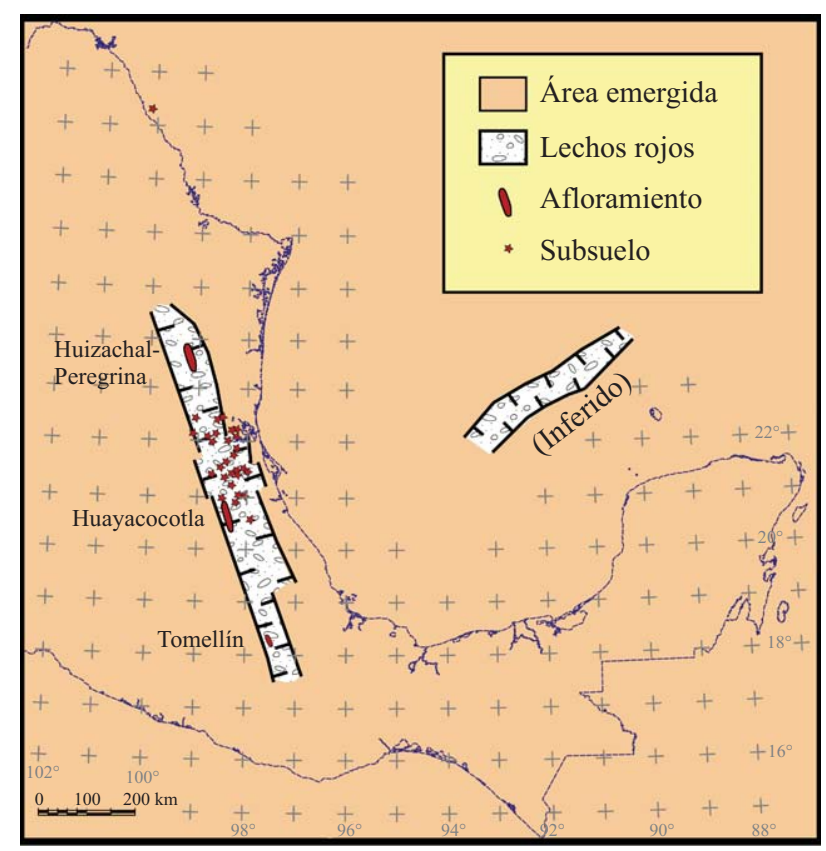

Figura 5. Paleogeografía del Triásico Superior en el área del Golfo de México. La ubicación de los horsts fué esquematizada por Salvador (1991c) con datos superficiales y de subsuelo. Las costas y las fronteras del país se muestran como referencia. 
el inicio del Jurásico Superior (Oxfordiano inferior), época en la cual la sedimentación continental estuvo totalmente controlada por procesos tectónicos distensivos. No se sabe que haya ocurrido sedimentación marina en la parte que hoy ocupa el Golfo de México, pero sí se conoce con certeza que al occidente estaba ocurriendo sedimentación marina contemporánea a la continental y que muy probablemente el mar inició su avance hacia el Proto-Golfo de México desde el Pacífico a través de la parte central de México, en lo que hoy es la zona de frontera entre los estados de Zacatecas y San Luis Potosí, en donde se han encontrado amonitas del Triásico Superior (Cantú-Chapa, 1969; Salvador, 1991b). El avance transgresivo de las aguas del Pacífico hacia el oriente fue invadiendo el área del actual Golfo de México para formar extensos cuerpos de aguas hipersalinas, con una circulación sumamente restringida y, quizá también un clima de tipo desértico, lo que favoreció el depósito de grandes volúmenes de evaporitas en la parte central del Golfo de México. Según Salvador (1991c), la etapa inicial de la fragmentación y separación de la Pangea para formar el Golfo de México duró del orden de unos $46 \mathrm{Ma}$, desde el Triásico Tardío (210 Ma) hasta el Jurásico Medio Tardío (169 Ma) (Salvador, 1991b) (Figura 2).

Es muy probable que durante la etapa temprana del proceso de rifting, la corteza continental sólo haya estado sujeta a hundimientos lentos y a ensanchamiento de los sistemas de grabenes que poco a poco fueron inundados por las aguas del Pacífico. La evidencia con que se cuenta en la actualidad indica que toda la sal del Golfo de México se depositó durante el Calloviano (164-159 Ma) (Salvador, 1991b), en una gran cuenca de miles de kilómetros cuadrados, que hoy se encuentra dividida en dos partes, una al norte y otra al sur, por una franja en donde no hay sal, de orientación aproximada este-oeste en la porción central del Golfo (Figura 6). Tal división sugiere que tuvo que existir en esa parte del Golfo una zona más alta y estrecha, asociada con la presencia de una cresta de generación de corteza oceánica que indujo el movimiento del bloque de Yucatán hacia el sur durante el Jurásico Temprano y Medio, y que separó las dos masas de sal, de las que la meridional se movió hacia el sur junto con Yucatán (Humpris, 1979; Salvador, 1987, 1991c). Sin embargo, aunque el proceso de rifting fue lento, el depósito de la sal fue relativamente rápido pues se realizó en un lapso de aparentemente cinco millones de años, durante el Calloviano. Si se compara la distancia horizontal que se movió el Bloque de Yucatán hacia el sur, estimada entre 470 y $520 \mathrm{~km}$ (Buffler y Sawyer, 1985; Pindell, 1985; Dunbar y Sawyer, 1987), con las decenas de metros que se hundieron los pisos de los grabenes triásicos (Figura 5) que subyacen los depósitos de sal, durante el mismo lapso de tiempo, es posible suponer que la región del Proto-Golfo debió haber tenido un relieve muy suave y una subsidencia muy lenta, mientras que horizontalmente se movió muy rápido, tal como lo evidencian las condiciones requeridas para el depósito de este tipo de evaporitas.

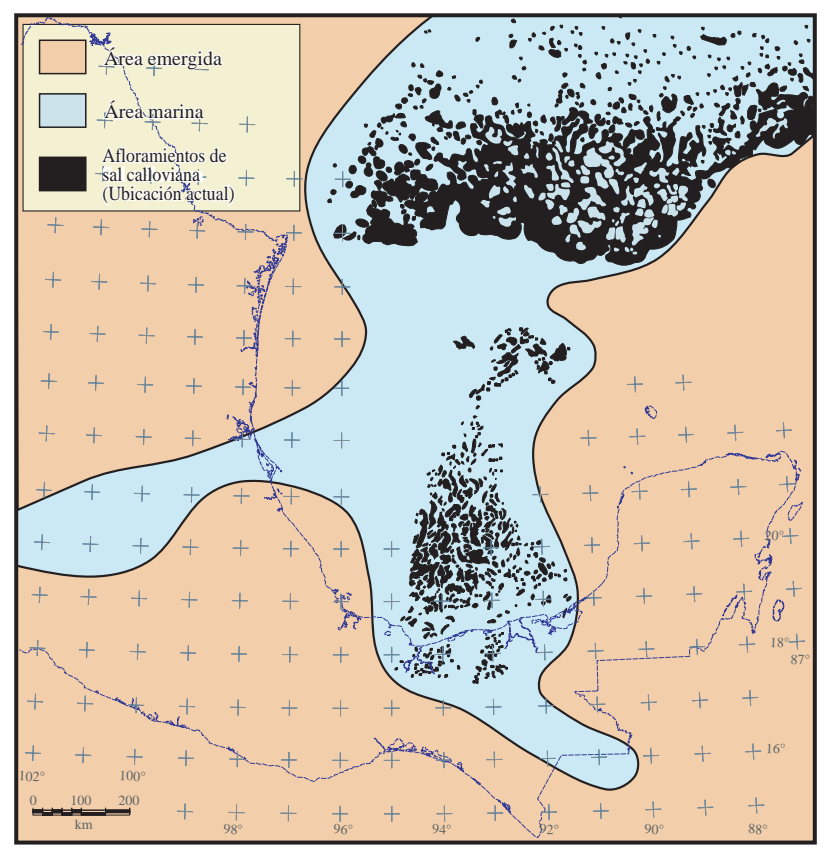

Figura 6. Paleogeografía del Jurásico Medio en el área del Golfo de México. En negro se muestra la distribución actual de la sal depositada durante el Calloviano. La sal aflora en el fondo marino en dos masas, una septentrional y otra meridional, separadas por una franja sin sal. Las costas y las fronteras del país se muestran como referencia.

En cuanto a la edad de la sal, la mayoría de los autores (Humpris, 1979; Salvador, 1987, 1991c; Pindell 1985, 1993) asignan al Calloviano a todas las masas que existen en el Golfo de México, pero es sabido que se tienen diferentes edades y posiciones estratigráficas para la sal autóctona en diferentes localidades, siendo más antiguas hacia el centro de la cuenca y más jóvenes hacia el borde de la misma, en donde también varía su litología a otro tipo de evaporitas. Las anhidritas que afloran en la región de Galeana, Nuevo León, tiene una edad del Oxfordiano (Padilla y Sánchez, 1986), al igual que los yesos de la Sierra de Minas Viejas (Díaz et al., 1959) y la sal de la Cuenca de La Popa (Lawton et al., 2001). Viniegra (1971), al igual que Imlay (1953), considera que parte de la sal del norte del Istmo de Tehuantepec es de edad post-Calloviano preOxfordiano Superior (Divesiano).

La masa de sal mayor se depositó primero en la parte central del Golfo de México, pero posteriormente, a medida que la invasión por aguas marinas iba progresando, se desarrollaron en sus bordes plataformas muy amplias en donde la circulación de las aguas era muy restringida, y estaban limitadas hacia el mar por largas barras de oolitas, que se extendían por cientos de kilómetros cuadrados alrededor del Golfo, condiciones que favorecieron el depósito de otras masas de sal en las zonas lagunares que bordeaban la cuenca. En el sureste mexicano las barras de oolitas jurásicas tienen una distribución extensa (ver la Figura 7 más adelante) y se han identificado claramente porque son las rocas productoras de hidrocarburos en campos gigantes 


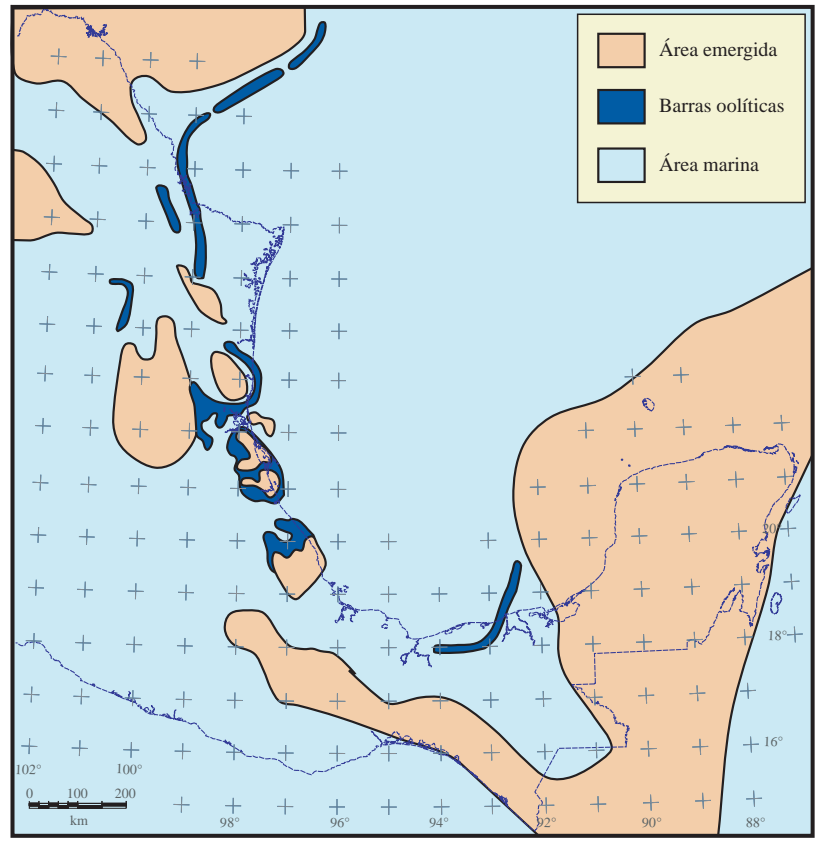

Figura 7. Paleogeografía del Kimmeridgiano temprano. Para este tiempo la actividad de la Falla Transformante Tamaulipas-Oaxaca ya había cesado su movimiento lateral y tanto el Macizo de Chiapas como el Bloque Yucatán ocuparon desde entonces la posición que tienen hoy. Las costas y las fronteras del país se muestran como referencia.

como Samaría y Sitio Grande (Santiago-Acevedo y MejíaDautt, 1980).

El movimiento del bloque de Yucatán hacia el sur se realizó a lo largo de dos sistemas de fallas transformantes que han recibido diferentes nombres por diversos autores, quienes también las han ubicado en sitios distintos. El sistema occidental fue denominado Falla Transformante Tamaulipas-Golden Lane-Chiapas por Pindell (1985), Falla Tamaulipas-Oaxaca por Robin (1982) y Padilla y Sánchez (1986) y denominado solamente como la "Transformante" por Salvador (1991c), mientras que el sistema oriental solamente ha sido mencionado pero no ha recibido un nombre más formal. En este trabajo se continua con el uso de la terminología definida en 1986 por el que escribe, principalmente porque la postulación de la falla Tamaulipas-Oaxaca está sustentada en evidencia geológica, paleogeográfica y geofísica, además de que ha sido correlacionada con las pocas localidades de serpentinitas en el oriente de México y por la estrecha relación que existe entre éstas y las trayectorias de fallas transformantes en otras partes del mundo (Dengo, 1972; Case, 1980; Delgado-Argote y Morales-Velázquez, 1984), aspecto que no ha sido considerado por Pindell ni por Salvador en alguno de los múltiples artículos que han publicado sobre el Golfo de México. Robin (1982) ha sugerido que esta falla constituye el límite entre los basaltos, andesitas y dacitas de la Franja Volcánica Trans-Mexicana y las rocas alcalinas e hiperalcalinas de la Planicie Costera del Golfo, además de que ha sido interpretada por Ramírez-Ramírez (1984) como el límite entre la corteza continental verdadera y la corteza continental atenuada de la margen occidental del Golfo de México. Finalmente, en el artículo publicado por Alaniz-Alvarez et al. (1996), se determinó que esta falla tuvo un movimiento de transcurrencia durante el Jurásico Medio ( 165 Ma).

Las zonas de debilidad cortical de mayor longitud de México son, de norte a sur: el Lineamiento de Texas (Hill, 1902; Muehlberger, 1965), los Lineamientos de Boquillas-Sabinas y de Sierra Mojada-China (Padilla y Sánchez, 1982), la Mega-Cizalla de Mojave-Sonora (Silver y Anderson, 1974; Anderson y Schmidt, 1983), la Falla Transformante de Tamaulipas-Oaxaca (Padilla y Sánchez,1986), la Transformante de Motagua-Polochic (Hess y Maxwell, 1963; McBirney, 1963; Dengo, 1968, 1969; Dengo y Bohnenberger, 1969; Muehlberger y Ritchie, 1975), la Megacizalla de Acapulco-Guatemala (Anderson y Schmidt, 1983), y la Falla Transformante de San Andrés (Atwater, 1970) (Figura 8). Todas ellas han sido involucradas en muchos modelos de tectónica de placas para explicar el origen del Golfo de México, pero es importante aclarar que el tiempo en el que estuvieron activas no es el mismo para todas ellas. La Megacizalla de Mojave-Sonora (Anderson y Schmidt, 1983) y el Lineamiento de Texas (Muehlberger, 1965) estuvieron activas durante el Paleozoico temprano, aunque recientemente, Molina-Garza e Iriondo (2005) proponen que la primera tuvo un movimiento transcurrente durante el Paleozoico tardío; los Lineamientos de Boquillas-Sabinas y de Sierra Mojada-China, sólo tuvieron actividad desde el Permotriásico hasta el Jurásico Medio y tampoco se movieron después de ese lapso (Padilla y Sánchez, 1982); mientras que la Falla Transformante Tamaulipas-Oaxaca tuvo un desplazamiento normal durante el Permotriásico y posteriormente un movimiento transcurrente durante el Calloviano, para volver a un movimiento normal después del Calloviano (Padilla y Sánchez, ibid). Por último, las fallas transformantes de Motagua-Polochic y la de San Andrés iniciaron su movimiento en el Neógeno y continúan moviéndose lateralmente en la actualidad.

La Falla Transformante Tamaulipas-Oaxaca tuvo un papel muy importante en la apertura y posterior evolución tectónica del Golfo de México, por las razones siguientes (ver Figura 8):

a. La forma de arco de círculo que tiene esta falla, apoya un deslizamiento lateral del Bloque Yucatán a lo largo de ella durante el Jurásico Temprano-Medio, que hace girar a Yucatán unos $49^{\circ}$ en sentido contrario al de las manecillas del reloj, lo cual es concordante con los datos paleomagnéticos de Guerrero-García (1975) y Pindell y Kennan (2003).

b. Al finalizar el Calloviano cambia su desplazamiento lateral nuevamente a vertical y actúa como un sistema de fallas normales que favorecen la subsidencia del piso del Golfo de México (Padilla y Sánchez, 1982; Alaniz -Alvarez et al., 1996). 


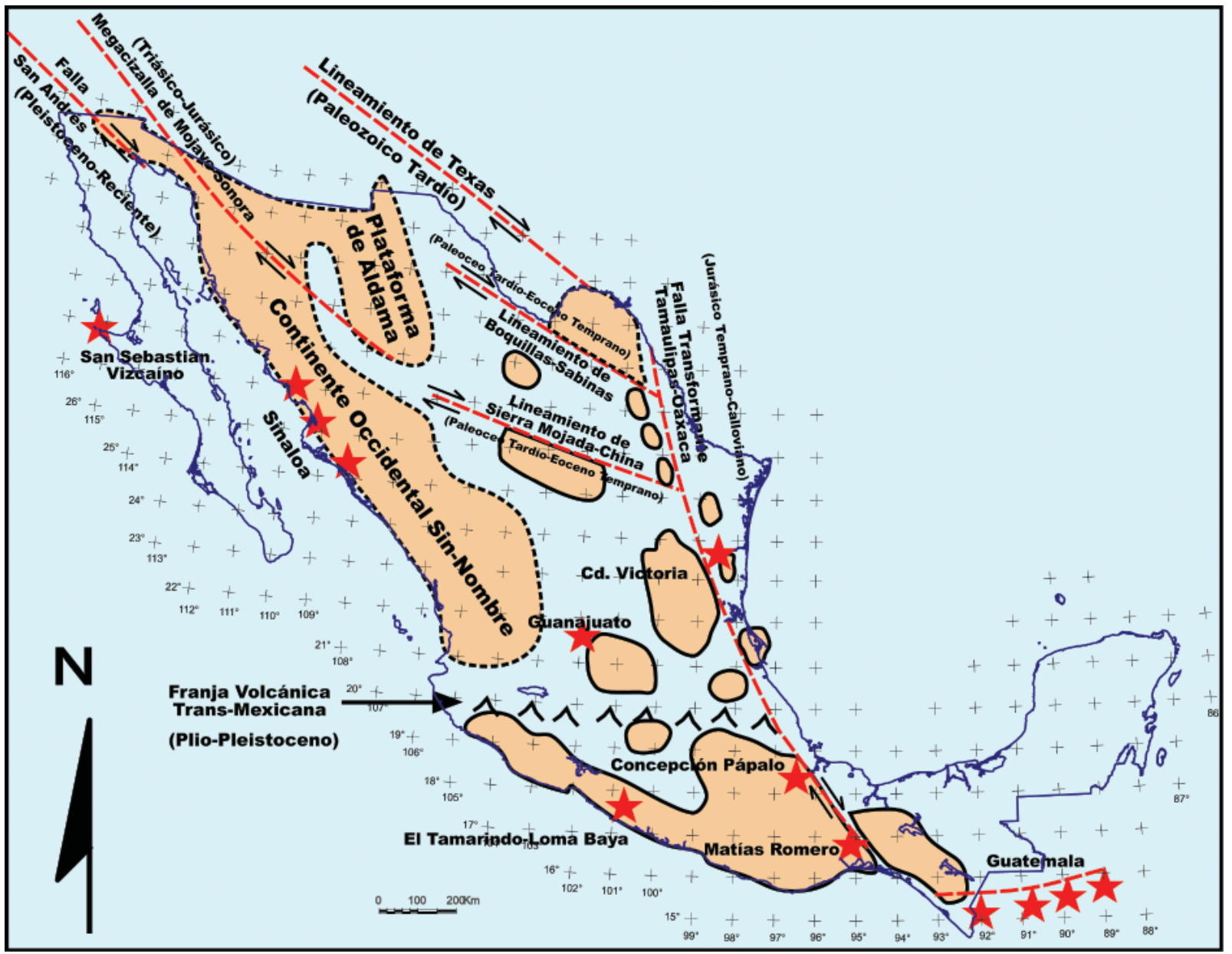

Figura 8. Estructuras regionales que afectan la corteza continental de México. La edad en la que las fallas tuvieron movimiento de desplazamiento lateral se muestra junto a cada una de ellas. Las estrellas rojas indican las localidades en donde afloran rocas básicas y ultrabásicas serpentinizadas. Modificada de Padilla y Sánchez (1986).

c. Constituye el límite entre la corteza continental verdadera y la corteza continental atenuada.

d. Es el conducto en el cual se emplazan las serpentinitas de Cd. Victoria, Concepción Pápalo (Dengo, 1972; Delgado-Argote y Morales-Velázquez, 1984) y Matías Romero (Figura 8).

e. Es el conducto para la actividad volcánica alcalina e hiperalcalina en la Planicie Costera del Golfo, además de ser el límite entre el vulcanismo dacítico-andesítico de la Franja Volcánica Trans-Mexicana y la mencionada Planicie Costera del Golfo.

f. El conjunto de fallas cuasi-paralelas que constituyen la Falla Transformante Tamaulipas-Oaxaca, limitan individualmente a los bloques de basamento que estuvieron emergidos durante el Mesozoico Temprano, como el Archipiélago de Tamaulipas, las plataformas de Valles-San Luis Potosí y Tuxpan, así como el Macizo de Teziutlán.

Al terminar el Calloviano el Bloque Yucatán alcanzó la posición que ocupa actualmente y desde entonces sólo estuvo sujeto a una subsidencia lenta pero continua, hasta la época del Plio-Pleistoceno, cuando comenzó a emerger. También al término del Calloviano, la falla Transformante Tamaulipas-Oaxaca detiene su movimiento lateral y comienza a moverse en sentido vertical, favoreciendo la subsidencia de bloques de basamento. En el sureste mexicano es particularmente importante ésta época porque es entonces cuando el Macizo de Chiapas, junto con el Bloque Yucatán, comienza a recibir sedimentos marinos en su porción norte. El Período Jurásico Tardío se caracterizó por ser una época de tranquilidad tectónica en la que una subsidencia lenta, asociada al desplazamiento divergente de las Placas de Norteamérica de las de Laurasia y Gonwana, propició las condiciones necesarias para el depósito de carbonatos y lodos calcáreos intercalados.

\section{Etapa posterior al rift y al movimiento de Yucatán desde el Jurásico Superior hasta el Cretácico Superior}

El proceso tectónico de rifting que dio paso a la apertura del Golfo de México terminó al fin del Calloviano, después 
de lo cual, durante el Oxfordiano, se desarrollaron amplias plataformas de aguas someras a todo lo largo de los bordes del protogolfo de México, en las que se depositaron grandes volúmenes de carbonatos, con extensas barras oolíticas en los bordes de plataforma (Salvador, 1991c; Winker y Buffler, 1988; Williams-Rojas y Hurley, 2001). Este período se caracteriza por el depósito de clásticos en las zonas litorales, por la abundancia de carbonatos en las plataformas y por el depósito de menores espesores de lutitas y carbonatos con intercalaciones delgadas de calizas argiláceas en las zonas de cuenca. De hecho estas asociaciones litológicas formaron bandas concéntricas muy bien definidas en los bordes del Golfo de México (Salvador, 1991b). Los bloques de basamento emergidos que formaban las paleoislas en el occidente del protogolfo de México continuaban afectando la sedimentación de la región, siendo el mayor aporte de clásticos los provenientes del área del Bloque Yucatán y del noroeste. Estas condiciones de subsidencia lenta y continua prevalecieron durante todo el Kimmeridgiano (Salvador, 1987, 1991b, 1991c) (Figura 7).

Para el Tithoniano, la velocidad de subsidencia se hizo más lenta y predominó la sedimentación de secuencias de estratificación delgada de lutitas y carbonatos, en las cuales aumentó considerablemente la presencia de organismos, probablemente favorecido por un clima templado. Los horsts formados en el basamento premesozoico bordeando la parte occidental del Golfo de México permanecieron emergidos y aportando sedimentos clásticos cada vez en menores cantidades a medida que el relieve topográfico disminuía. En las áreas costeras de estas islas continuó el depósito de rocas clásticas, grandes lagunas litorales y de barras oolíticas en los extremos de las plataformas. En el suroeste del Golfo también se desarrollaron amplias plataformas someras que se extendían hasta el Macizo de Chiapas y el occidente del Bloque Yucatán que continuaban aportando clásticos. En ellas se depositaron también grandes volúmenes de carbonatos y, probablemente, también algunos depósitos de sal en la parte noroccidental del Macizo de Chiapas (Viniegra, 1971), aunque no se tiene evidencia concluyente al respecto. Las condiciones de estabilidad tectónica y climática fueron máximas, favoreciendo así la proliferación de vida. En este período se depositaron en la cuenca lutitas muy ricas en materia orgánica, con delgadas intercalaciones de carbonatos, que son la roca generadora de la mayoría de los inmensos volúmenes de hidrocarburos que existen en el Golfo de México, especialmente en el sureste mexicano (González y Holguín, 1992) (Figura 9). La estabilidad tectónica fue tan grande que las rocas depositadas conservaron características litológicas muy similares en toda la cuenca del Golfo de México; las islas que bordeaban el occidente del Golfo todavía estaban emergidas y continuaban aportando sedimentos clásticos a las zonas litorales, mientras que en las plataformas predominaba el depósito de calizas arcillosas con abundantes concreciones fosforíticas

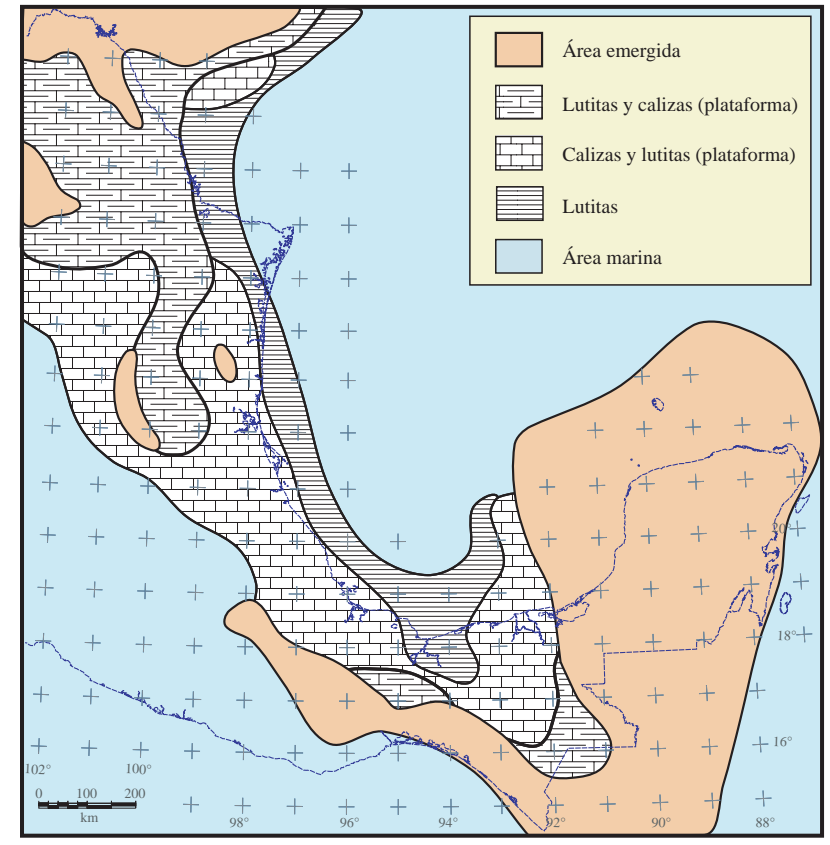

Figura 9. Paleogeografía del Tithoniano superior. Nótese la gran extensión de las áreas de plataformas someras, en donde ocurrió el depósito de rocas ricas en materia orgánica que constituyen la principal roca generadora de hidrocarburos en el Golfo de México. Las costas y las fronteras del país se muestran como referencia.

ricas en fósiles, sobre todo en el noreste de México. En el sureste mexicano las condiciones de depósito fueron similares a las anteriores, como se ha constatado en datos de subsuelo y en afloramientos al norte del Macizo de Chiapas, en donde su edad se determinó con amonitas (Quezada-Muñetón, 1984).

Hacia fines del Tithoniano continuaba la gran invasión de los mares en el Golfo de México y se inició la sumergencia de la porción meridional de Florida (Salvador, 1991b). La mayoría de las islas del occidente del Golfo de México fueron cubiertas por los mares jurásicos, pero permanecieron emergidas la parte noroeste de la Península de El BurroPeyotes, las Islas de Tamaulipas, Coahuila, pequeñas islas en el área de Tampico, el Macizo de Teziutlán, el Macizo de Chiapas y el Bloque Yucatán (Figura 9). Al occidente de México se incrementó la actividad volcánica, como lo indica la presencia de numerosas capas de bentonita y pedernal negro en capas, lentes y nódulos en el norte de Veracruz (Viniegra, 1966).

El espesor de las rocas del Tithoniano varía en el sur (Tabasco) y el occidente del Golfo de México (Veracruz y Tamaulipas) de 400 a $500 \mathrm{~m}$ y disminuye a aproximadamente $100 \mathrm{~m}$ en el área de Saltillo; en el noreste de México y el subsuelo del sur de Texas, tiene entre 500 y $700 \mathrm{~m}$, pero en el norte de Louisiana el espesor se incrementa considerablemente hasta alcanzar cerca de 1,200 m (Salvador, 1991b), en donde además contiene una proporción mayor de arenas. 
Las condiciones tectónicas estables persistieron en la región durante el Cretácico Temprano, a la vez que las islas del Archipiélago de Tamaulipas, el Macizo de Chiapas y el Bloque Yucatán continuaban su lenta subsidencia y el mar las iba cubriendo progresivamente. El depósito de clásticos en los bordes de los altos de basamento del Archipiélago de Tamaulipas aún emergidos seguía disminuyendo, a la vez que aumentaba el depósito de carbonatos (Winker y Buffler, 1988). El área de las ya extensas plataformas seguía incrementándose y enormes volúmenes de carbonatos fueron depositados sobre la mayor parte de México. De hecho puede decirse que las condiciones tectónicas de estabilidad del Tihoniano se extendieron hasta todo el Neocomiano, con la diferencia de que la proporción de lutitas intercaladas en las calizas de inicios del Cretácico fueron decreciendo hasta casi desaparecer a fines del Valanginiano. Los espesores de las calizas y lutitas depositadas durante el Berriasiano y el Valanginiano, raramente exceden los $500 \mathrm{~m}$ en el noreste, centro y sureste de México.

Para el Neocomiano Superior (HauterivianoBarremiano), 132 a $121 \mathrm{Ma}$, aumentó la velocidad de subsidencia de las plataformas que bordeaban el Golfo de México, favoreciendo así el depósito de gruesos paquetes de carbonatos con menores cantidades de lutitas intercaladas y con espesores superiores a los 1,500 m en promedio. Secuencias menos gruesas se depositaron en las zonas más profundas de la cuenca mientras que en los bordes de las plataformas se formaban largas franjas de arrecifes de rudistas alrededor de las áreas anteriormente emergidas así como alrededor de toda la cuenca del Golfo de México (Winker y Buffler, 1988). Durante este tiempo el Archipiélago de Tamaulipas fue totalmente cubierto por los mares y sólo quedaron emergidos los bloques altos de basamento de la Isla de Coahuila, el Macizo de Chiapas y parte del Bloque Yucatán, en cuyos litorales continuó la sedimentación clástica. El depósito de evaporitas continuó en extensas áreas de plataformas someras con circulación restringida, como la Cuenca de Sabinas, la zona de postarrecife de la Plataforma de Valles-San Luis Potosí y la parte occidental de la Plataforma de Yucatán, aunque la edad de estas evaporitas aún está bajo discusión (Salvador, 1991b) (Figura 10).

Durante el Aptiano ocurrió un cambio en la velocidad de subsidencia que favoreció el depósito de una mayor cantidad de lutitas intercaladas con capas delgadas de carbonatos en una sección condensada. Después de un período de 23 millones de años, de subsidencia continua y progresiva en el que se depositaron más de 2,000 m de carbonatos casi puros, correspondientes a las formaciones Cupido y Tamaulipas Inferior, al inicio del Aptiano se inició el depósito de lutitas intercaladas con capas delgadas de carbonatos que según Goldhammer (1999) y Goldhammer y Johnson (2001) fue causado por una rápida elevación del nivel del mar. Durante este período, que duró aproximadamente cinco millones de años, el mar cubrió definitivamente los altos de basamento que habían estado

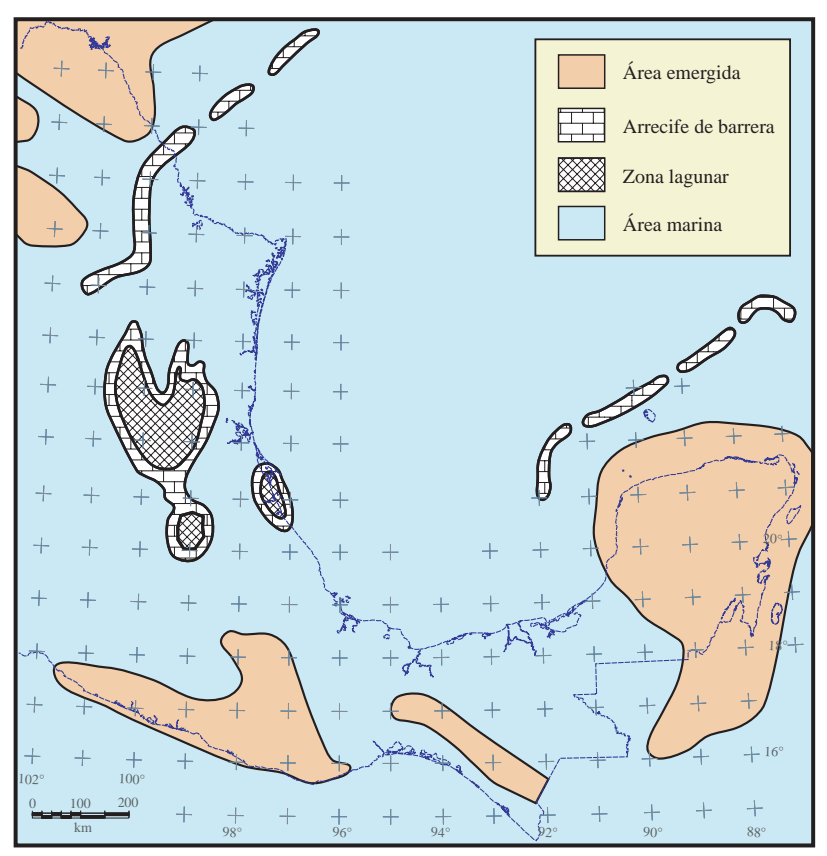

Figura 10. Paleogeografía del Barremiano. Note la longitud de las barreras de arrecifes que bordean a las plataformas, así como la gran extensión de áreas con carbonatos de aguas someras. Las costas y las fronteras del país se muestran como referencia.

emergidos desde los inicios de la transgresión marina ligada a la apertura del Golfo de México en el Triásico Tardío. Este evento tectónico es claro en las regiones de Texas y el norte y centro-oriente de México (Formaciones La Peña y Otates), pero no es así en el suroeste del Golfo de México, en las Sierras de Zongolica y Chiapas, ni tampoco en la cadena plegada y sepultada de Reforma-Akal, en donde la sedimentación de carbonatos continuó como había venido ocurriendo desde principios del Cretácico y no existe en la columna sedimentaria evidencia alguna de una elevación súbita del nivel del mar. Es por esta razón que en opinión del que escribe, es poco probable que haya habido una variación notable del nivel del mar que sólo hubiera dejado huella en el noreste de la cuenca del Golfo de México. Todo parece indicar que más bien hubo una mayor velocidad de subsidencia en el noroeste del Golfo de México que en el resto del mismo.

Por otro lado, las largas franjas de arrecifes que se habían venido desarrollando en los bordes de los altos de basamento desde el Neocomiano, continuaron desarrollándose en el occidente y oriente del Golfo de México, mientras que en el noreste de México se volvieron más esporádicas a medida que los mares iban transgrediendo las paleoislas hasta cubrirlas totalmente a fines del Aptiano (comparar las Figuras 10 y 11).

Después del Aptiano, durante el Albiano y el Cenomaniano, continuó la subsidencia general del Golfo de México, a una velocidad aproximadamente constante en toda la cuenca, lo que permitió que se desarrollaran 
otra vez, largas cadenas de arrecifes de barrera ubicados aproximadamente arriba de las franjas arrecifales neocomianas, es decir, aproximadamente sobre los bordes de los altos de basamento de las paleoislas de Coahuila y Valles-San Luis Potosí y la Plataformas de Tuxpan y de Córdoba (Figura 11). El espesor de los cuerpos arrecifales depositados en este lapso indica que la velocidad de subsidencia fue mayor que aquella del Neocomiano. Las áreas que muestran alguna diferencia notable en el sur de México, como por ejemplo las plataformas de Artesa y Mundo Nuevo, estuvieron afectadas por el desalojo de sal calloviana que generó elevaciones del fondo marino, que a su vez causaron claras discordancias regionales en el sureste mexicano, como se ha observado en numerosas líneas sísmicas inéditas propiedad de Pemex (Angeles Aquino et al., 1992; García-Molina, 1994)).

El Turoniano marca otro cambio importante en los patrones de sedimentación del Golfo de México, porque termina el predominio del depósito de carbonatos. Este cambio fue más evidente en las porciones occidental y noroccidental de la cuenca, pero no lo fue tanto en la parte meridional de la misma, en donde la sedimentación de carbonatos continuó prácticamente invariable hasta el término del Cretácico. Durante esta época, en las plataformas se depositaron capas delgadas de calizas y lutitas (Formaciones Indidura y Guzmantla), mientras que en la cuenca se depositaban calizas con abundantes nódulos y capas de pedernal (Formaciones Agua Nueva y Maltrata). Tales patrones de depósito sugieren que la subsidencia en el Golfo de México fue mayor en su borde occidental-noroccidental que en el meridional.

Con base a los afloramientos abundantes a lo largo de la Sierra Madre Oriental y a los datos del subsuelo que existen en pozos en la Planicie Costera del Golfo, se infiere que durante el Coniaciano y el Santoniano se incrementó la actividad volcánica en el occidente de México, lo cual se reflejó en la sedimentación marina del Golfo de México, en donde continuó el depósito de capas delgadas de calizas y lutitas, pero con abundantes horizontes intercalados de bentonita, abarcando todas las plataformas del borde occidental y meridional del Golfo, mientras que en la cuenca continuaba el depósito de carbonatos con bandas y nódulos de pedernal con delgadas intercalaciones de bentonita (Salvador 1991b).

Para el fin del Período Cretácico, durante el Campaniano y el Maestritchiano, aumentó el aporte de sedimentos clásticos provenientes del oeste de México, mientras que en el occidente del Golfo de México la subsidencia aumentó y se depositaron gruesos espesores de margas y lutitas de la Formación Méndez (Figura 12). En varias localidades a lo largo de la Sierra Madre Oriental se han reportado horizontes delgados de bentonita (Padilla y Sánchez, 1986), que indican que la actividad volcánica en el occidente continuó hasta casi el fin del Cretácico. Algunos bloques altos de basamento no se movieron con la misma velocidad de subsidencia regional y permanecieron en posición más

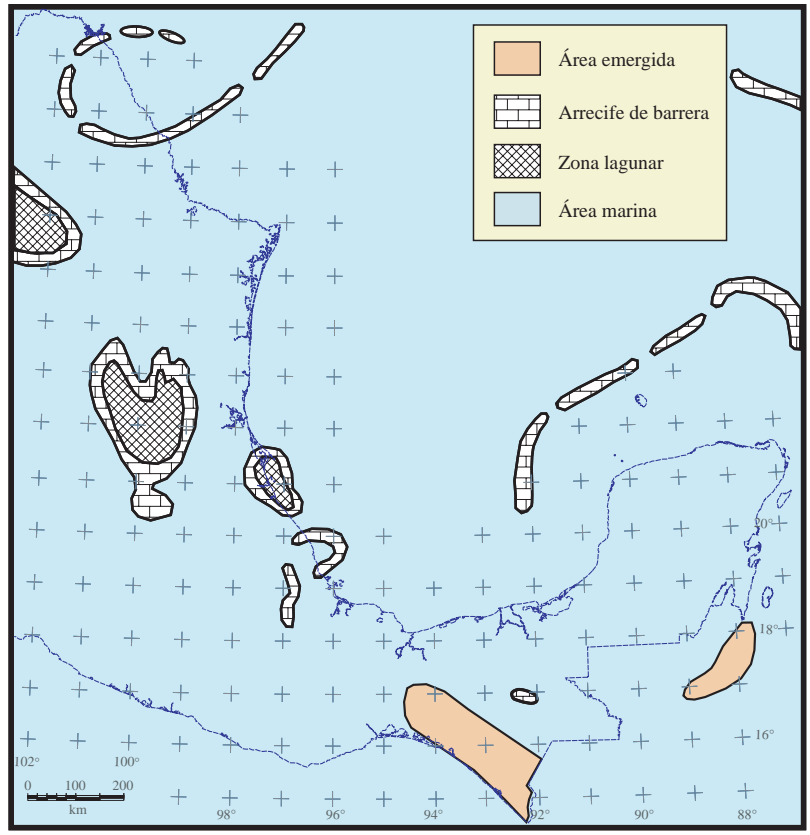

Figura 11. Paleogeografía del Albiano-Cenomaniano. La sedimentación de clásticos prevaleció sobre los carbonatos hasta el Aptiano tardío, tiempo en el que los altos de basamento que estuvieron emergidos desde el Jurásico tardío fueron sumergidos bajo las aguas del mar. A partir de entonces la sedimentación de carbonatos dominó nuevamente en toda la cuenca del Golfo de México. Las costas y las fronteras del país se muestran como referencia.

alta que los demás, como ha sido observado en la margen oriental de la Plataforma de Valles-San Luis Potosí, en donde la Lutita Méndez descansa discordante sobre las calizas arrecifales Albiano-Cenomanianas de la Caliza El Abra, que presenta en este nivel de discordancia rasgos cársticos bien desarrollados (Aguayo, 1978). Más al sur, en las cercanías del Macizo de Chiapas se depositaban clásticos (Fm. Angostura), mientras que en las zonas de la Sierra de Chiapas, la Cuenca de Veracruz y la Plataforma de Córdoba, las lutitas y margas de la Formación Méndez cambiaban lateralmente a facies carbonatadas de aguas someras (Prost y Aranda, 2001; Jennette et al., 2003).

\section{Etapa de deformación y sedimentación durante el Cenozoico}

Otro cambio importante en la evolución tectónica del Golfo de México ocurre en el límite entre el Período Cretácico y el Período Paleógeno, cuando se ha postulado que en el área de Chicxulub, en la costa norte de Yucatán, ocurrió el impacto de un cuerpo extraterrestre al que se considera responsable de la extinción de numerosas especies animales y vegetales, entre las que destacan los dinosauros y las amonitas (Alvarez et al., 1992). Coincidente con esta edad, existe una brecha en carbonatos que tiene una gran extensión en el sur del Golfo de México y tiene 


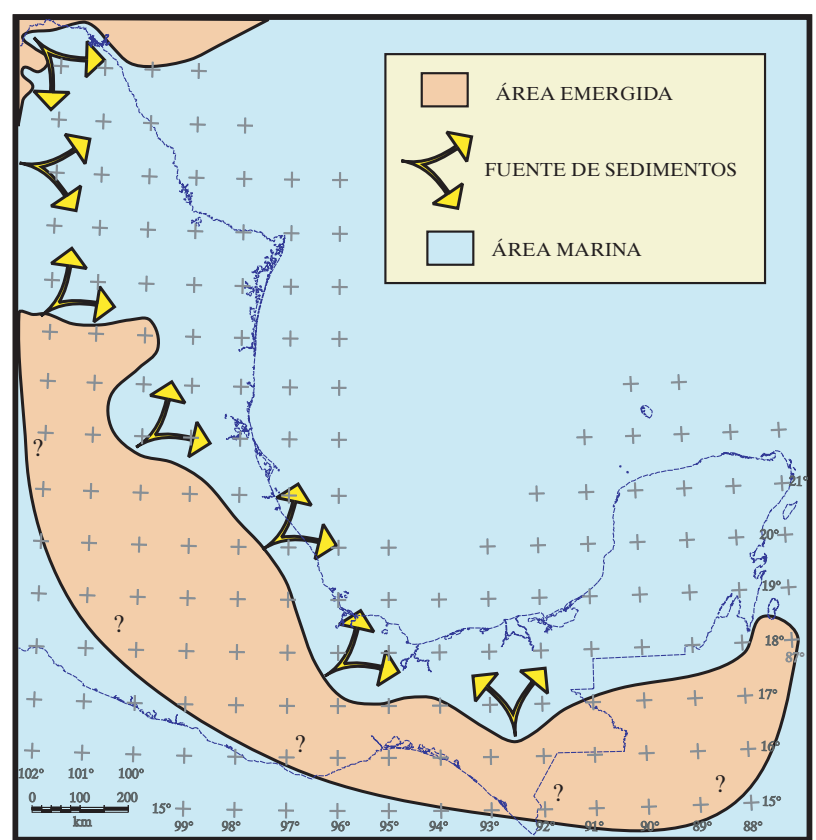

Figura 12. Paleogeografía del Turoniano-Maestrichtiano. El aporte de sedimentos provenientes del occidente y del sur se incrementó y cambió definitivamente el patrón de depósito de carbonatos a clásticos. Esta condición se mantuvo hasta el Cenozoico. Las costas y las fronteras del país se muestran como referencia.

también una gran importancia económica para el país, por ser la roca almacén de los grandes campos petroleros del área marina del sureste de México (Figura 13). Esta brecha denominada internamente en Pemex como "Brecha K-T" es inusual porque tiene una extensión de miles de kilómetros cuadrados y gruesos espesores que alcanzan hasta los $700 \mathrm{~m}$ en algunas localidades (Akal). Además, en gran parte de su espesor carece de matriz, por lo que su permeabilidad es asombrosamente alta. No es una tarea fácil explicar el origen de un cuerpo sedimentario de esas dimensiones, formado por fragmentos angulares de caliza de diversos tamaños, sin matriz en la mayoría de las localidades conocidas, aunque en algunas (Akal y $\mathrm{Ku}$ ), en unos cuantos horizontes, la matriz tiene la misma litología que los clastos. Sin embargo, su origen ha sido explicado de varias formas, de la cuales tres son las más aceptadas: la primera aduce que el impacto de un cuerpo extraterrestre (meteorito o cometa) en Chicxulub fué la causa de la formación de la brecha (Grajales-Nishimura et al., 2000), lo cual implica que el tamaño de grano de los depósitos en su eyecta, fueran menores a una distancia mayor del sitio del impacto, condición que no se cumple; la segunda argumenta que la brecha fue el producto de un derrumbe submarino de los fragmentos de caliza que descansaban en el talud del Escarpe de Campeche cuando ocurrió el impacto del cuerpo extraterrestre hace $65.5 \mathrm{Ma}$ (AngelesAquino et al., 1992; Limón-González et al., 1994), pero si esta fue la causa del depósito de la brecha, entonces su forma y distribución deberían ajustarse a una morfología

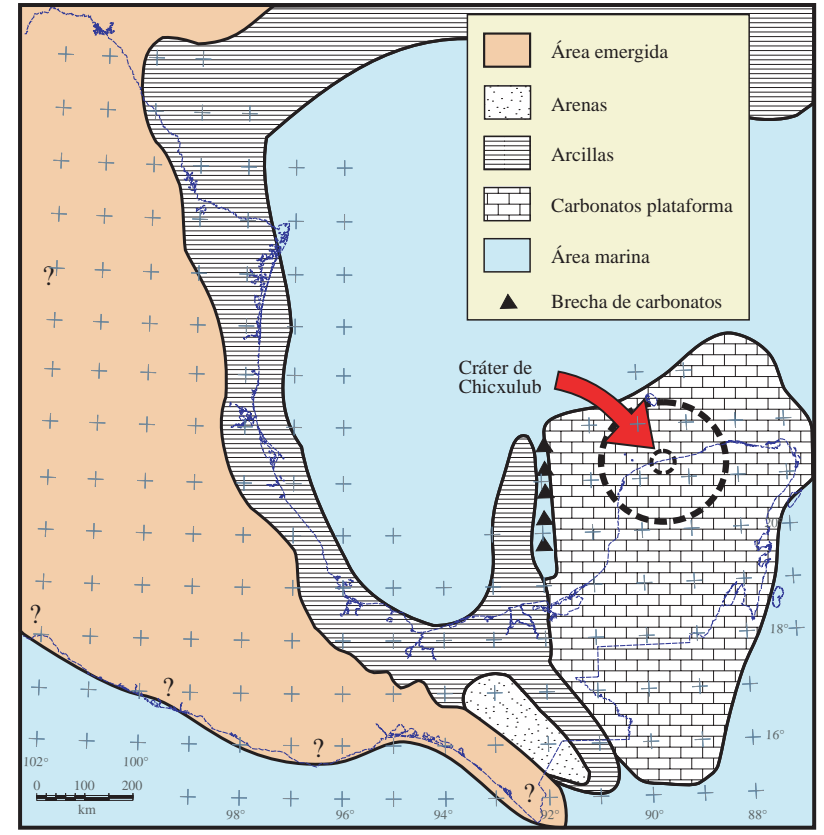

Figura 13. Paleogeografía de inicios del Paleoceno, cuando se ha propuesto el impacto de un meteorito en el área de Chicxulub. En este tiempo se depositó una brecha de carbonatos con una gran extensión y espesores que alcanzan los $700 \mathrm{~m}$. Las costas y las fronteras del país se muestran como referencia.

alargada, paralela al escarpe y con una variación del tamaño de grano de la brecha, de mayor a menor, en dirección de la cuenca; por último, la tercera atribuye el origen de la brecha a condiciones de carsticidad por exposición subaérea de los carbonatos depositados en extensas planicies de intermareas, lo cual explicaría la extensión territorial, aunque el espesor requeriría un movimiento de subsidencia súbito del orden de $700 \mathrm{~m}$ para justificar la edad de la brecha $(65.5$ Ma). El que escribe considera que una sola de las hipótesis anteriores es insuficiente para explicar las dimensiones volumétricas de la brecha, así como las condiciones físicas de su depósito, pero quizá las tres hipótesis juntas pudieran justificar el origen de la misma.

A fines del Cretácico el aporte de sedimentos clásticos del noroeste y del occidente del Golfo de México se incrementó notablemente durante las primeras pulsaciones de la Orogenia Laramide, también conocida como Orogenia Hidalgoana (de Cserna, 1989). La Era Cenozoica se inicia prácticamente con el evento tectónico que dió origen a las cadenas plegadas y cabalgadas del occidente del Golfo de México, específicamente las Sierras y Cuencas de Coahuila, la Sierra Madre Oriental y la Sierra de Zongolica, desde el Paleoceno tardío hasta el Eoceno temprano (Padilla y Sánchez, 1982). La orogenia fue el resultado de la convergencia de la Placa Farallón por debajo de la Placa Norteamericana, en la que el fragmento de corteza oceánica que estaba en subducción tuvo un ángulo muy bajo, causando así una deformación a mayor distancia de la zona de la trinchera y elevando una porción considerable de la parte 
meridional de la Placa de Norteamérica. Esta condición tectónica favoreció el incremento del aporte de grandes volúmenes de sedimentos clásticos después del fin de la orogenia, que empezaron a depositarse en las cuencas formadas en el antepaís de las cadenas plegadas, que de norte a sur se conocen como las Cuencas de Parras-San Carlos (CPSC), de Tampico-Misantla (CTM) y de Veracruz (CV) (de Cserna, 1989; Padilla y Sánchez, ibid) (Figura 14).

Así como durante el Cretácico la forma y el tamaño de la cuenca del Golfo de México estuvieron determinados por las plataformas carbonatadas, a partir del Eoceno tardío la nueva forma de la cuenca dependió totalmente del gran flujo de la sedimentación clástica. Se empezaron a desarrollar grandes fallas lístricas normales asociadas a depocentros en las cuencas de antepaís. Durante este tiempo se depositaron gruesos espesores de arenas finas en los talúdes del occidente del Golfo de México, Planicie Costera del Golfo, al tiempo que los sedimentos más finos iban rellenando las partes más profundas Goldhammer (1999).
Como consecuencia del aporte masivo de sedimentos la sal y la arcilla de la parte meridional del Golfo de México empezaron a mobilizarse, formando "rollers", diapiros, lenguas y canopies, así como también contribuyendo a la sobrepresurización de las masas de arcilla.

Para el Eoceno tardío se formaron los depocentros de la Cuenca de Veracruz y se inició su relleno con sedimentos clásticos derivados del oeste (Figura 14) (Jennette et al., 2003).El límite oriental de esta cuenca estaba constituido por el Alto de Santa Ana y el Macizo de Teziutlán (Viniegra, 1966), dos de los bloques de basamento que bordeaban la porción occidental del antiguo Golfo de México como la continuación sur del Archipiélago de Tamaulipas. Se considera que el depósito de 5 a 7 kilómetros de espesor de sedimentos acumulados durante el Eoceno y el Mioceno fueron favorecidos por una fuerte subsidencia por flexión de la corteza en el antepaís de la Sierra de Zongolica, sin que hasta el momento se hayan identificado fallas regionales que limiten la cuenca (Prost y Aranda, 2001). En

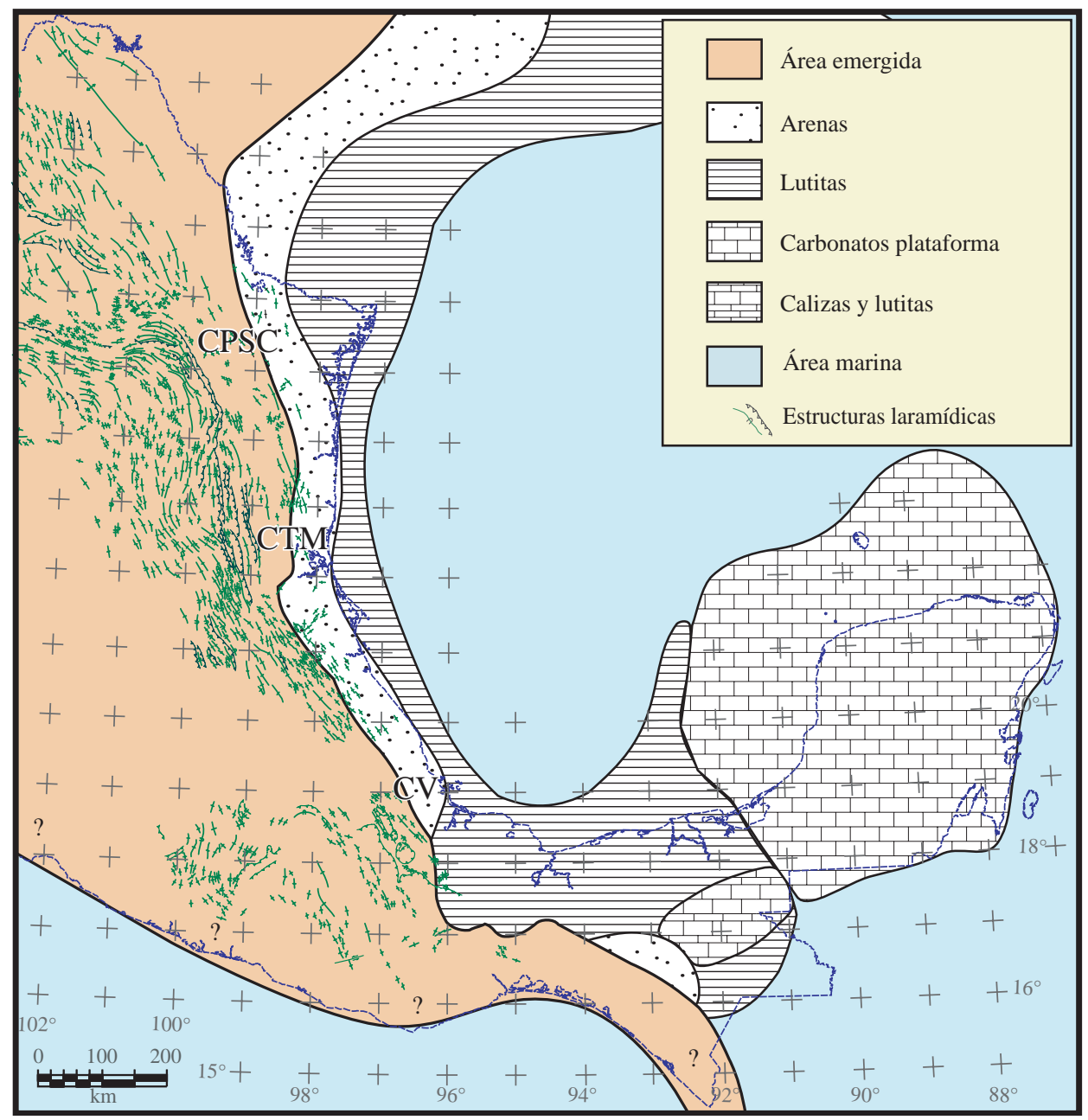

Figura 14. Paleogeografía del Eoceno tardío cuando se inició el relleno de las cuencas de antepaís de las sierras plegadas y cabalgadas del occidente del Golfo de México por sedimentos. Cuenca de Parras-San Carlos (CPSC), Cuenca de Tampico-Misantla (CTM) y Cuenca de Veracruz (CV). Las costas y las fronteras del país se muestran como referencia. 
líneas sísmicas se ha observado que existe una antiforma supratenue para el Oligoceno temprano en el área de Los Tuxtlas, que forma una clara discordancia regional; este alto dentro de la cuenca puede significar una zona que la divide en dos depresiones suaves, una al oriente y otra al occidente (Figura 15). Cruz-Helú et al. (1977) reconocieron una discordancia mayor cerca de la base de la sección marina miocénica, pero su edad exacta no fue identificada, sin embargo, se sabe que el Mioceno inferior se acuña hacia el oeste sobre las rocas carbonatadas plegadas y afalladas por la Laramide (Salvador, 1991c). El resto de la columna del Mioceno y el Plioceno están representados por una gruesa secuencia de clásticos. La máxima actividad volcánica en la Cuenca de Veracruz ocurrió durante el Plioceno y el Cuaternario, al igual que en la Franja Volcánica Transmexicana y en el centro volcánico de Los Tuxtlas. Estos episodios volcánicos del Plioceno fueron los causantes del levantamiento de la porción oriental de la Cuenca de Veracruz (Salvador, ibid) La paleogeografía de fines del Eoceno se muestra en la Figura 14, tiempo en el ya existían las estructuras compresionales de la Orogenia Laramide.

Aunque Prost y Aranda (2001) han postulado la presencia en el subsuelo de una falla de desplazamiento lateral sinistral, orientada $\mathrm{N} 20^{\circ} \mathrm{W}$, en el área de Novillero-Víbora, ellos mismos reconocen que no se ha encontrado evidencia de su existencia, quizá porque fue interpretada sólo con base a un incremento en el espesor de los sedimentos hacia el occidente de la cuenca y a un arreglo ligeramente escalonado de los pliegues superficiales que sobreyacen el área. Por otro lado, al oriente de la cuenca, en el anticlinal de Novillero, Aranda-García (1999) dató los estratos de crecimiento relacionados con este pliegue como del Oligoceno al Mioceno inferior, lo cual le confiere esa edad a la estructura. También al oriente de la cuenca se ha identificado un sistema mayor de fallas denominado Los
Tuxtlas-Anegada, el cual se extiende a través del Campo Volcánico de Los Tuxtlas con una dirección N $50^{\circ} \mathrm{W}$ y continúa en el mar con una dirección $\mathrm{N} 40^{\circ} \mathrm{W}$ a lo largo de la margen oriental del Alto de Anegada (Jacobo et al., 1992); esta falla ha sido mapeada en el campo y en imágenes de satélite, además de en el subsuelo, por lo que existe una alta probabilidad de que sea la expresión actual superficial de la Falla Transformante Tamaulipas-Oaxaca (Figura 1 y 15)., que estuvo activa durante el Jurásico Medio cuando se abrió el Golfo de México (Padilla y Sánchez, 1986; Alaniz-Alvarez et al., 1996).

Durante el Mioceno Medio la dirección del movimiento de la Placa de Cocos cambió hacia el noreste, generando la compresión que deformó a la Cuenca de Veracruz (Jacobo et al., 1992; Prost y Aranda, 2001). Este proceso estuvo acompañado por un levantamiento térmico en los altos de Anegada y de Los Tuxtlas (Jacobo et al., 1992), lo que causó la conocida discordancia del área (Mossman y Viniegra, 1976). En las partes más profundas de la Cuenca de Veracruz se depositaron después del Mioceno Medio del orden de 4 a $5 \mathrm{~km}$ de sedimentos (Figura 1). En el talud continental, al oriente de las cuencas de Burgos, TampicoMisantla y de Veracruz, se desarrolló un deslizamiento gravitacional, de los sedimentos del talud, hacia la cuenca del Golfo de México, limitado echado arriba por una serie de fallas de crecimiento y, echado abajo, por una falla inversa de bajo ángulo que corta toda la sección Paleógena y Neógena. La columna estratigráfica Miocena-Pleistocena (Figuras 2 y 3) está deformada en una serie de grandes pliegues aproximadamente paralelos, con longitudes de onda de 10 a $12 \mathrm{~km}$ y relieves desde $300 \mathrm{~m}$ hasta de $1 \mathrm{~km}$, conocidos como las Crestas Mexicanas, o también como las Crestas Ordoñez (Figuras 1 y 16).

El origen de las Cuencas del Sureste está íntimamente ligado con la Sierra de Chiapas y con la Cadena Plegada de Reforma-Akal. Según Santiago-Acevedo et al. (1984), a
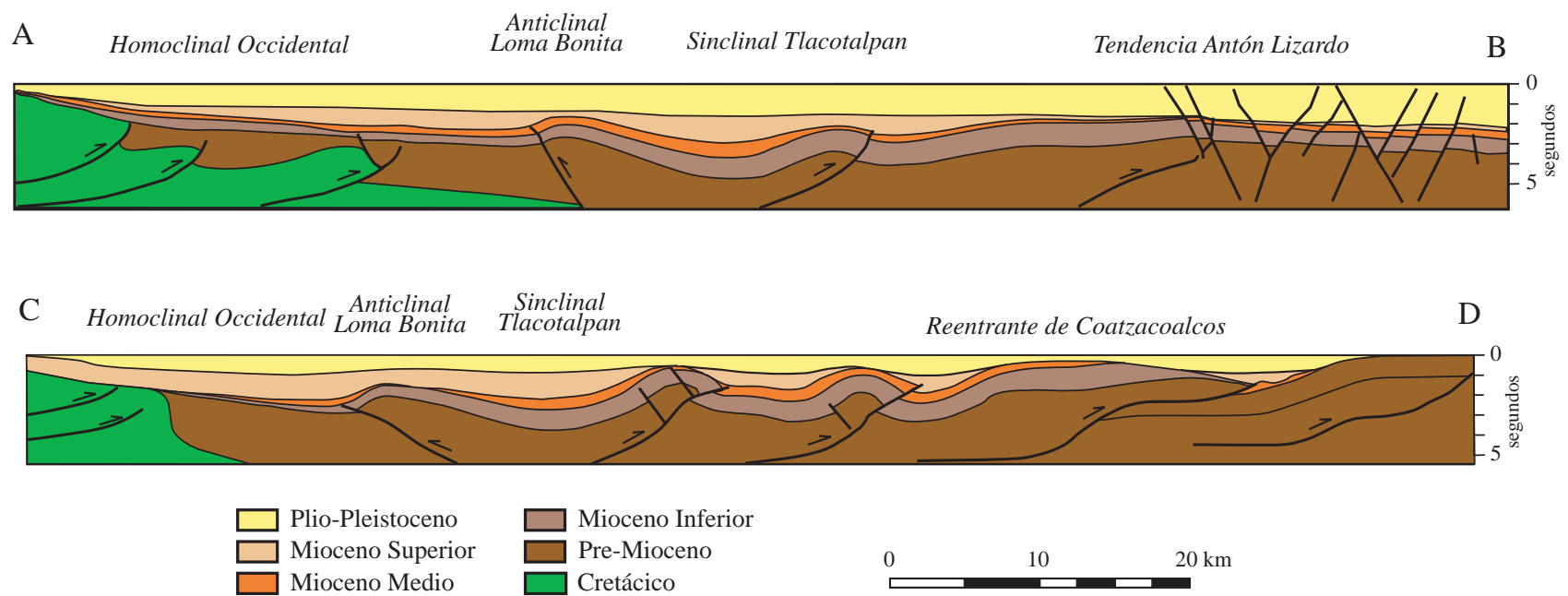

Reentrante de Coatzacoalcos D

Figura 15. Secciones geológicas de la Cuenca de Veracruz. Su localización se muestra en la Figura 1. Modificada de Jennette et al. (2003). 
principios del Paleógeno, el Macizo de Chiapas continuaba emergido en su parte sur, mientras que sobre las rocas carbonatadas marinas (de plataforma en Chiapas y de cuenca en Campeche) de su parte norte, se depositaban gruesas secuencias de clásticos con espesores que varían de 2,500 m en la zona de Campeche (Pozo Ateponta 1), hasta cerca de 3,000 m en Chiapas (Pozo Triunfo 101).

De acuerdo con Ambrose et al. (2003), durante el Oligoceno continuó el depósito de clásticos en todo el sureste mexicano, aunque en el área de Macuspana se empezó a desarrollar un depocentro en donde se depositaron gruesas secuencias de arcillas. Al mismo tiempo, sobre la Cadena Chiapas-Reforma-Akal se depositaron espesores menores de arenas y arcillas, mientras que en el área de ComalcalcoSalina del Istmo comenzó la movilización hacia el norte, de grandes volúmenes de sal en forma de almohadillas y "rollers" (Angeles Aquino et al., 1992).

Los mismos patrones sedimentarios continuaron hasta el Mioceno temprano, pero en el Mioceno medio
(Serravaliano, 12.0 Ma) ocurrió la máxima etapa de deformación que plegó y cabalgó las rocas de la cadena de Chiapas-Reforma-Akal, con un nivel de décollement en la cima de la sal calloviana y una vergencia hacia el norte. Sánchez-Montes de Oca (1980) denominó a esta orogenia como Evento Chiapaneco (Figura 16). Durante este evento el Macizo de Chiapas también se acortó, por lo que GarcíaMolina (1994) considera que existe otro nivel de despegue profundo dentro del bloque de basamento.

Hacia fines del Mioceno e inicios del Plioceno, después de la deformación compresiva del Evento Chiapaneco, se inició el basculamiento hacia el norte de la Cadena de Chiapas-Reforma-Akal, como una respuesta al desalojo de la sal calloviana en la misma dirección (Figuras 2 y 17). El gran aporte de clásticos provenientes del Macizo de Chiapas durante el Plioceno y el Pleistoceno, causó el depósito de varios kilómetros de espesor de sedimentos, cuya sobrecarga empezó a generar grandes fallas de crecimiento orientadas NE-SW, con sus bloques caídos hacia el norte.

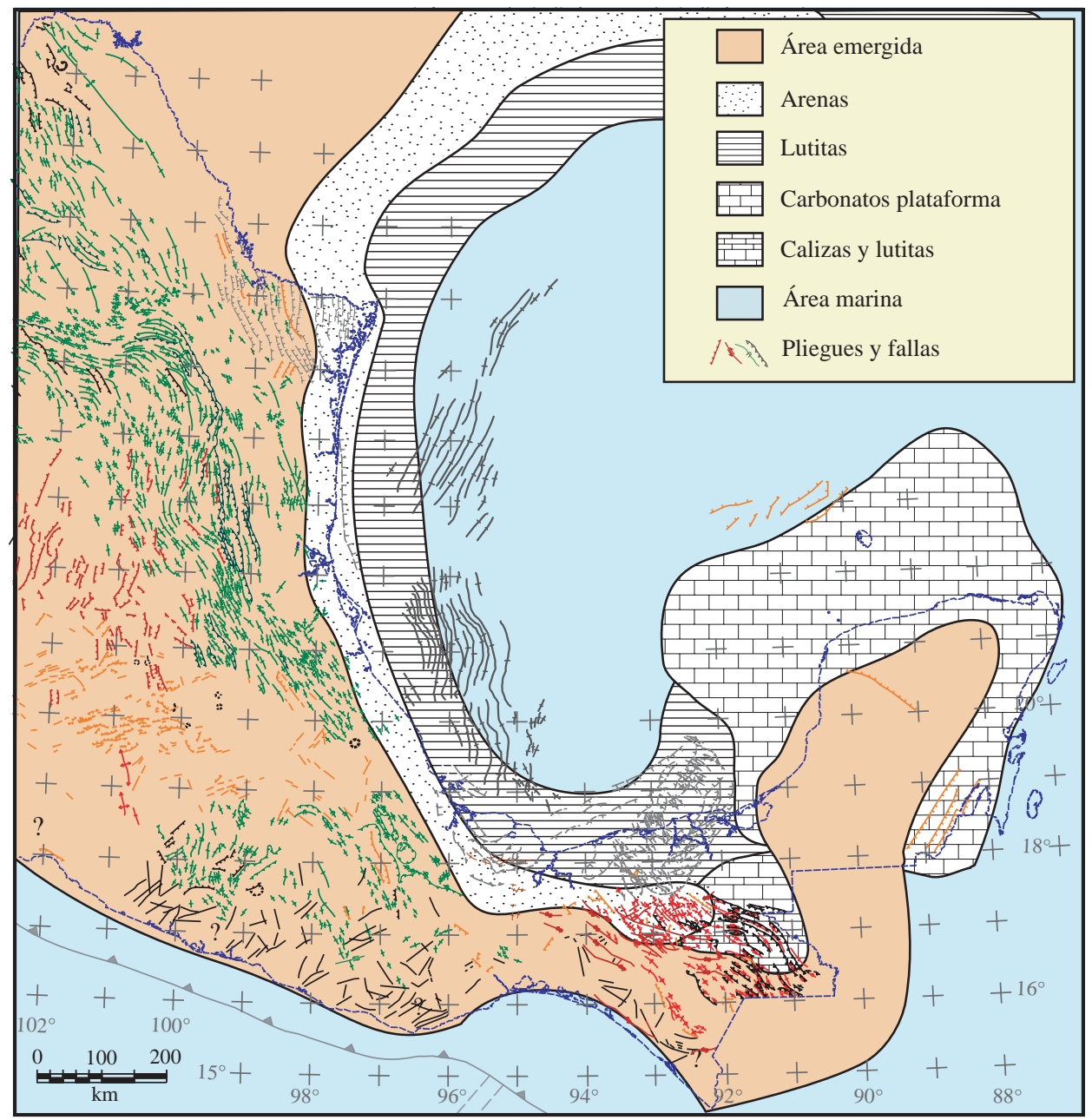

Figura 16. Paleogeografía del Mioceno tardío, cuando ya se habían formado las Crestas Mexicanas y los pliegues y fallas de la Cuenca de Veracruz, y de la Sierra de Chiapas-Reforma-Akal. De éstas últimas estructuras, el tramo Reforma-Akal se conoce solamente en el subsuelo. Las costas y las fronteras del país se muestran como referencia. 
En la Figura 17 se observa que la orientación de estas fallas sintéticas es casi perpendicular a la dirección de los pliegues formados durante el Evento Chiapaneco, y en la Figura 18 se ilustra de manera esquemática la relación tectónica entre las estructuras compresionales del Evento Chiapaneco y la estructuras extensionales que las sobreyacen.

Las mayores fallas lístricas normales del PlioPleistoceno se formaron en las cuencas de Macuspana y de Comalcalco-Salina del Istmo, mientras que espesores menores de sedimentos clásticos eran depositados también sobre la Cadena Chiapas-Reforma-Akal. Una diferencia que es notable entre estas cuencas consiste en que, mientras en la cuenca de Comalcalco-Salina del Istmo se desalojaba sal (Ricoy, 1989), en la de Macuspana se desalojaba arcilla (Ambrose et al., 2003). En las secciones geológicas regionales de las Figuras 19 y 20 se muestran las estructuras de las cuencas de Comalcalco-Salina del Istmo y Macuspana, así como las estructuras de la cadena plegada de ChiapasReforma-Akal.
Las secuencias depositadas en la cuenca de Macuspana estuvieron bajo un régimen de extensión desde el Mioceno tardío hasta el Pleistoceno, tiempo en el que sufrieron una inversión tectónica (Ciclo Cascadiano según SánchezMontes de Oca, 1980), que formó los pliegues anticlinales que hoy constituyen las trampas de los yacimientos de esta zona (Ambrose et al., 2003). En la Figura 20 se observan los pliegues característicos de inversión tectónica en el área del Campo José Colomo. También en las Cuencas de Comalcalco y Salina del Istmo se sabe que ocurrió inversión tectónica, pero no se han publicado los datos correspondientes.

Finalmente, la deformación del sureste mexicano ocurrió en el Neógeno (Figuras 2 y 21) en el orden siguiente: 1. Plegamiento y fallamiento de la Cadena Plegada y Cabalgada de Chiapas-Reforma-Akal durante el Mioceno medio (Figura 21b), con un despegue al nivel de la sal del Calloviano y otro dentro del basamento del Macizo de Chiapas.

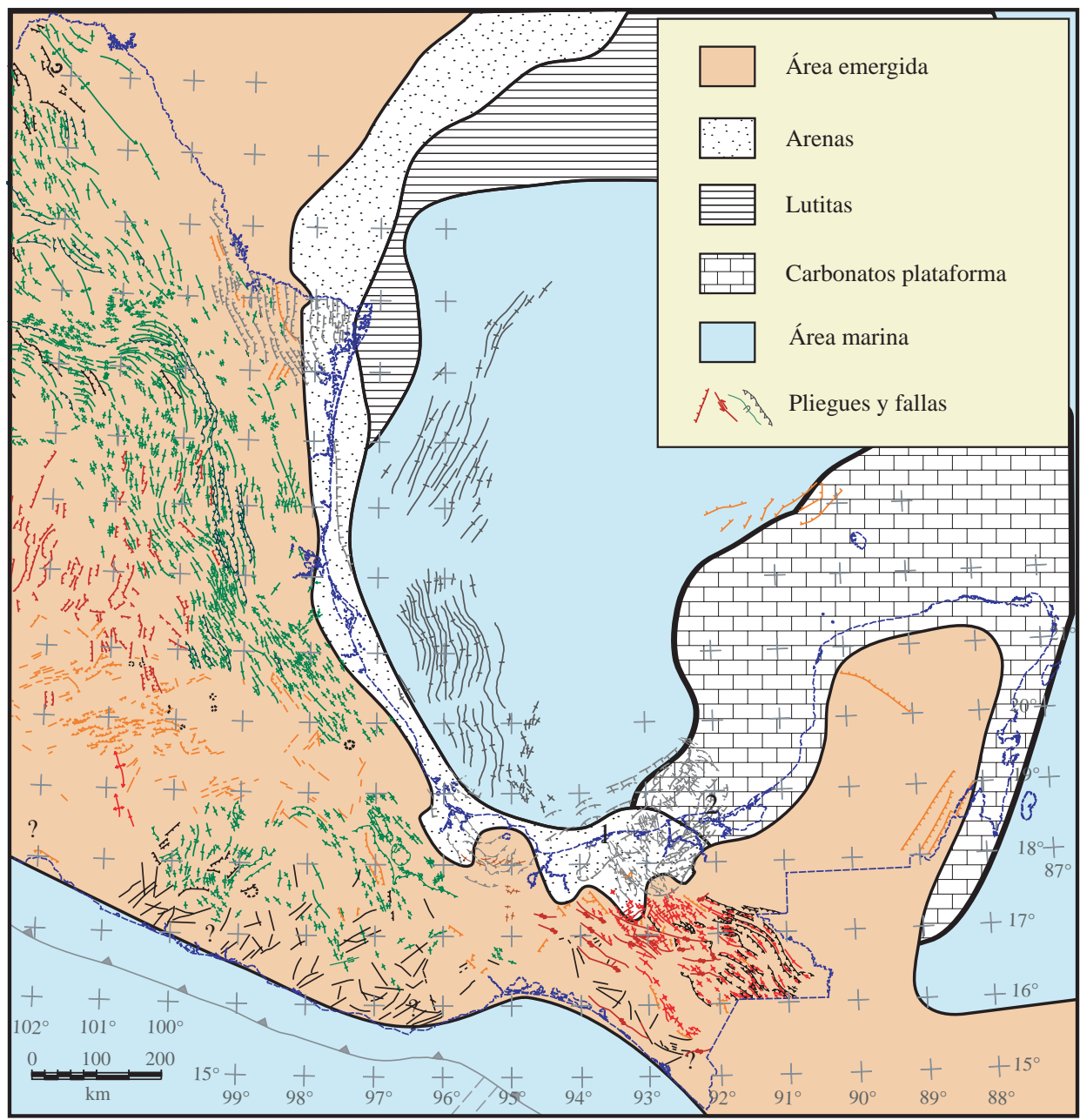

Figura 17. Paleogeografía del Pleistoceno Tardío. En este tiempo ya había ocurrido el basculamiento hacia el norte de la cadena Sierra de ChiapasReforma-Akal por el desalojo de sal calloviana y se habían formado las cuencas de (1) Comalcalco-Salina del istmo y (2) Macuspana. La orientación de las estructuras extensionales, casi perpendicular a las compresionales. Las costas y las fronteras del país se muestran como referencia. 


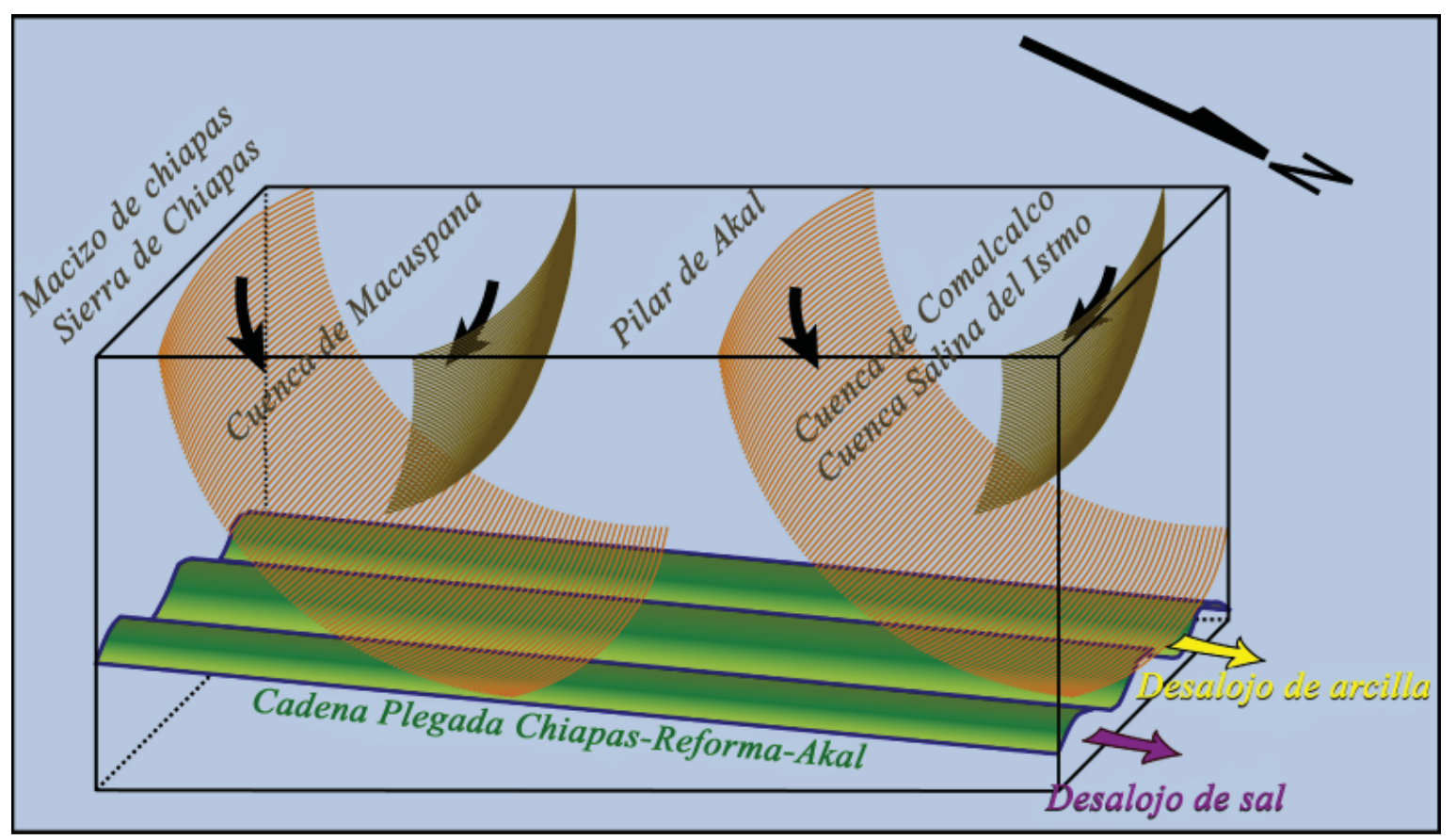

Figura 18. Bloque diagramático que muestra la disposición espacial de la Cadena Plegada de Chiapas-Reforma-Akal, basculada hacia el NW y las cuencas de Macuspana y Comalcalco producto de un deslizamiento gravitacional.

2. Basculamiento, hacia el noreste, de la cadena plegada durante el Mioceno tardío.

3. Depósito de gruesos espesores de arcillas durante el Mioceno tardío.

4. Deslizamiento gravitacional de la columna Paleógena tardía sobre las arcillas miocénicas.

5. Formación de la cuenca de Comalcalco durante el Plioceno (Figura 21c).

6. Formación de la cuenca de Macuspana en dos etapas: las fallas que la limitan al sureste y al noroeste se formaron durante el Plioceno y las fallas oblicuas escalonadas este-oeste se formaron durante el Pleistoceno y hasta el Reciente (Figura 21c). En ambos casos las arcillas del Mioceno favorecieron el décollement de la columna.

\section{Conclusiones}

La evolución tectónica y sedimentaria del Golfo de México se caracterizó por una subsidencia lenta que comenzó desde el Jurásico Medio y continúa hasta hoy. Durante el Jurásico y el Cretácico se depositaron varios kilómetros de espesor de sedimentos carbonatados en las extensas plataformas someras que bordeaban la cuenca. A inicios del Paleógeno, la Orogenia Laramide deformó las rocas de la parte occidental del Golfo, formando los pliegues y fallas de las Sierras Madre Oriental y la de Zongolica, mientras que en el sureste mexicano continuaba la sedimentación de carbonatos sobre la parte norte del macizo de Chiapas y sobre el Bloque Yucatán. En el
Mioceno medio el Evento Chiapaneco forma la cadena plegada y cabalgada de Chiapas-Reforma-Akal, a partir de un décollement a nivel de la sal calloviana, formando pliegues orientados NW-SE y con vergencia al noreste. Asociado al nivel de despegue, un volumen importante de sal se movilizó hacia el norte-noroeste, causando a su vez que las estructuras de la cadena de Chiapas-ReformaAkal se bascularan en la misma dirección y crearan así nuevos depocentros, en donde desde entonces hasta fines del Neógeno, se depositaron varios kilómetros de espesor de sedimentos clásticos (Figuras 18 y 21b), que empezaron a deslizarse por gravedad también hacia el norte-noroeste, o sea, hacia la misma dirección en la que se inclinaban los pliegues de la cadena Reforma-Akal. El peso de estos sedimentos propició que la secuencia discordante miocénica tardía comenzara un deslizamiento gravitacional hacia el NNW, iniciando así grandes fallas normales lístricas, orientadas WSW-ENE, es decir, casi perpendiculares a la orientación de los pliegues de la cadena Chiapas-Reforma-Akal (Figuras 21b y 21c); estas fallas normales regionales, sintéticas y antitéticas, constituyeron los limites de las cuencas de Comalcalco-Salina del Istmo y de Macuspana. Posteriormente, durante el Pleistoceno, las cuencas recién formadas bajo un régimen tectónico extensional sufren una compresión, desarrollándose en ellas pliegues propios de inversión tectónica, más evidentes en el campo José Colomo de la Cuenca de Macuspana (Figura 20). Una síntesis cronológica de los eventos tectónicos que afectaron el Golfo de México meridional y occidental se ilustra en la Figura 2. 

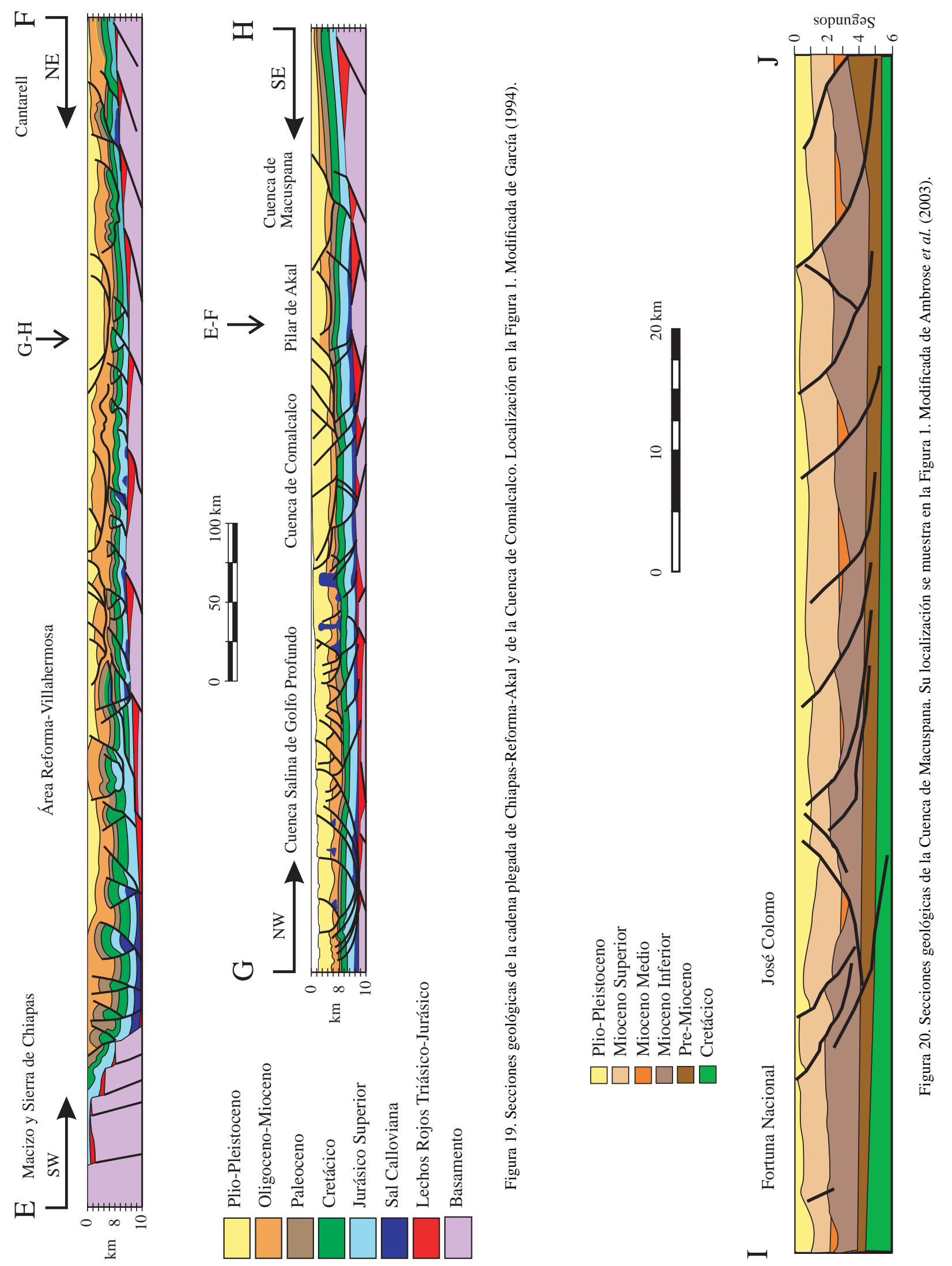


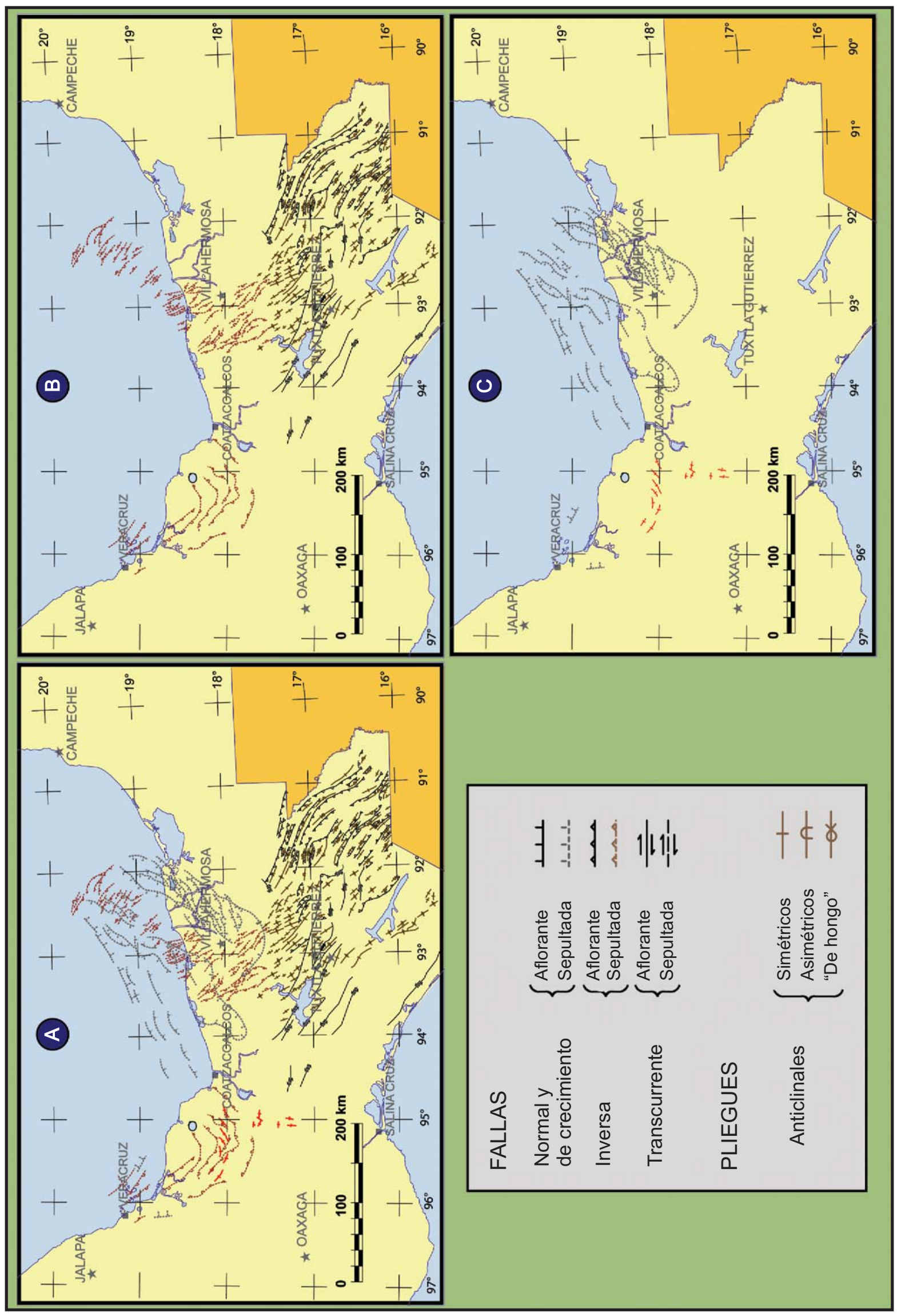

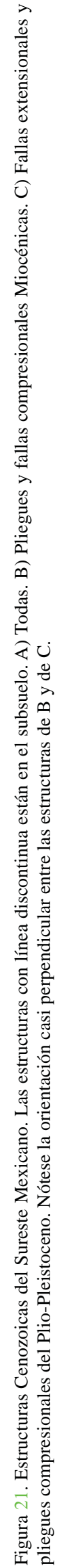


Finalmente, además del interés geológico, el sureste mexicano tiene una importancia económica muy grande para el país, porque en las estructuras de la cadena plegada y cabalgada de Chiapas-Reforma-Akal y en las Cuencas del Sureste se ubican el $89 \%$ de las reservas probadas de petróleo crudo equivalente y el $92 \%$ de la producción total de petróleo crudo equivalente del país (PEMEX, 2005). Las rocas del Tithoniano fueron las generadoras de hidrocarburos, mismos que se almacenaron en trampas estratigráficas y estructurales del Jurásico (Kimmeridgiano), Cretácico Superior-Paleoceno y del Neógeno.

\section{Agradecimientos}

El autor agradece a S. Alaníz-Alvarez, a A. F. NietoSamaniego y a dos árbitros anónimos por las revisiones críticas hechas al manuscrito, sus observaciones y comentarios fueron acertados, aún con las diferencias propias de estilo de escritura del autor. Agradezco también a aquellos compañeros de Pemex que me enriquecieron con sus datos inéditos sobre la tectónica del sureste mexicano y a los que me es imposible mencionar por temor a omitir a alguno.

\section{Rereefencias bibligráficas}

Aguayo C., J. E., 1978, Sedimentary environments and diagenesis of a cretaceous reef complex, eastern Mexico: Inst. Cienc. Mar y Limn., Universidad Nacional Autónoma de México, Anales, V. 5, P. $83-140$

Alaníz-Alvarez, S. A., P. van der Heyden, Nieto-Samaniego, A. F., Ortega-Gutiérrez, F., 1996, Radiometric and kinematic evidence for Middle Jurassic strike-slip faulting in southern Mexico related to the opening of the Gulf of Mexico: Geology, v. 24, p. 443-446

Alvarez, M., Jr., 1949, Tectonics of Mexico: American Association of Petroleum Geologists Bull. V. 33, No 8, p. 1319-1335

Alvarez, M., Jr., 1951, Mexico: American Association of Petroleum Geologists Bull. V. 35, No 2, p. 361-381

Alvarez, W., Smit, J., Lowrie, W., Asaro, F., Margolis, S.V., Claeys, P., Kastner, M., and Hildebrand, A.R., 1992, Proximal impact deposits at the Cretaceous-Tertiary boundary in the Gulf of Mexico: A restudy of DSDP Leg 77 Sites 536 and 540: Geology, v. 20, p. 697-700

Ambrose, W. A., T. F. Wawrzyniec, K. Fouad, S. C. Talukdar, R. H. Jones, D. C. Jennette, M. H. Holtz, S. Sakurai, S. P. Dutton, D. B Dunlap, E. H. Guevara, J. Meneses Rocha, J. Lugo, L. Aguilera, J. Berlanga, L. Miranda, J. Ruiz Morales, R. Rojas, and H. Solís, 2003 , Geologic framework of upper Miocene and Pliocene gas plays of the Macuspana Basin, southeastern Mexico: American Association of Petroleum Geologists Bulletin, v. 87, pp. 1411-1435

Anderson, T.H., and Schmidt, V.A., 1983, The evolution of Middle America and the Gulf of Mexico-Caribbean sea region during Mesozoic time: Geological Society of America Bull., v. 94, p. 941-966

Angeles Aquino, F.J., Reyes Núñez, J., Quezada-Muñetón, J.M., 1992, Evolución tectónica de la Sonda de Campeche, estilos estructurales resultantes y su implicación en la generación y acumulación de hidrocarburos: II Simposio de Exploración Petrolera, Instituto Mexicano del Petróleo, México, D.F.

Angeles Aquino, F.J. y Cantú-Chapa, A., 2001, Subsurface Upper Jurassic Stratigraphy in the Campeche Shelf, Gulf of Mexico, in, Bartolini, C., Buffler, R.T. y Cantú-Chapa, A., (Editores), The Western Gulf of Mexico Basin: Tectonics, Sedimentary Basins, and Petroleum Systems: American Association of Petroleum Geologists Memoir 75

Aranda-García, M., 1999, Evolution of Neogene contractional growth structures, southern Gulf of México: M.S. thesis, The University of Texas at Austin, $169 \mathrm{p}$.

Atwater, T., 1970, Implications of plate tectonics for the Cenozoic tectonic evolution of western North America. Bull. Geol. Soc. Amer., v. 81, p. 3513-3536

Bartolini, C., Buffler, R.T. y Cantú-Chapa, A., (Editores), 2001, The Western Gulf of Mexico Basin: Tectonics, Sedimentary Basins, and Petroleum Systems: American Association of Petroleum Geologists Memoir 75, $480 \mathrm{p}$.

Böse, E., 1905, Reseña acerca de la geología de Chiapas y Tabasco: Bol. Inst. Geol. México, p. 429-441

Böse, E., 1906, Escursion à l'Isthme de Tehuantepec: Xème Congr. Internal., Escursion XXXI

Buffler, R.T., y Sawyer, D.S., 1985, Distribution of crust and early history, Gulf of Mexico Basin: Gulf Coast Association of Geological Societies Trans., v. 35, p. 333-344

Burckhardt, C., 1930, Etude synthétique sur le Mésozoique Mexicain, Premiére partie: Societé Paléontologique Suisse Mémoires, v. 49, p. $1-123$

Burkart, B., 1983, Neogene North American-Caribbean plate boundary across northern Central America: Offset along the Polochic Fault: Tectonophysics, v. 99, p. 251-270

Burkart, B., Deaton, B.C., Dengo, C., y Moreno, G., 1987, Tectonic wedges and offset Laramide structures along the Polochic fault of Guatemala and Chiapas, Mexico: Reaffirmation of large Neogene displacement: Tectonics, v. 6, p. 411-422

Burkart, B., y Scotese, C.R., 1990, The Orizaba fault zone: Link between the Mexican Volcanic Belt and strike-slip faults of Northern Central America: EOS, American Geophysical Union Trans., v. 71, p. 1559

Cantú-Chapa, A., 1969, Una nueva localidad del Triásico Superior marino en México: Revista del IMP, v. 1, p. 71-72

Carfantan, J.C., 1986, Du Système Cordillérain Nord-Américain au Domaine Caraibe: Étude Géologique du Mexique Meridional: Tesis de Doctorado de Estado, Université de Savoie, Chambery, 557 p.

Case, J.E., 1980, Crustal setting of mafic and ultramafic rocks and associated ore deposits of the Caribbean regions, USGS Open File Report 80-304, 95 p.

Castillo-Tejero, C., 1955, Bosquejo estratigráfico de la Cuenca Salina del Istmo de Tehuantepec: Bol. Asoc. Mex. Geol. Petrol., v. 7, p. $175-212$

Contreras, V.H., 1959, Reseña de la geología del sureste de México: Bol. Asoc. Mex. Geol. Petrol., v. 11, p. 401-484

Cruz-Helú, P., Verdugo V., R., y Bárcenas P., R., 1977, Origin and distribution of Tertiary conglomerates, Veracruz Basin, Mexico: American Association of Petroleum Geologists Bull., v. 61, p. 207-226

Cserna, Z. de, 1989, An outline of the geology of Mexico: The Geology of North America - An overview: Vol. A, The Geological Society of America, p. 233-264

Delgado-Argote., L.A., y Morales-Velázquez, J.E., 1984, Rasgos geológicos y económicos del complejo básico-ultrabásico de El Tamarindo, Guerrero: Revista GEOMIMET, v. 128, p. 81-96

Dengo, G., 1968, Estructura geológica, historia tectónica y morfología de América Central: México, D.F., Centro Regional de Ayuda Técnica, $52 \mathrm{p}$.

Dengo, G., 1969, Problems of tectonic relations between Central America and the Caribbean, in: Geology of the American Mediterranean, Gulf Coast Association of Geological Societies Trans., v. 19, p. 311-320

Dengo, G., 1972, Review of Caribbean serpentinites and their tectonic implications, in: Shagan et al. (Eds.), Studies in Earth and Space Sciences: Geological Society of America, Memoir 132, p. 303312

Dengo, G., y Bohnenberger, O.H., 1969, Structural development of northern Central America: American Association of Petroleum 
Geologists Memoir 11, p. 203-212

Díaz G., T., Mixon, R., y Murray, G.E., 1959, Mesozoic Stratigraphy and Structure, Saltillo-Galeana Areas, Mexico: South Tex. Geol. Soc. Field Trip Guidebook, p. H1-H6

Dunbar, J.A. y Sawyer, D.S., 1987, Implications of continental crust extension for plate reconstruction: An example from the Gulf of Mexico: Tectonophysics, v. 6, p. 739-755

García-Molina, G., 1994, Structural evolution of SE México (ChiapasTabasco-Campeche) offshore and onshore: Rice University, Ph.D. Dissertation, $161 \mathrm{p}$.

Gibson, J.B.,1936a, Estratigrafía y tectónica de la zona costera del Golfo entre el $19^{\circ} 34^{\prime}$ latitud Norte y el Río Coatzacoalcos, Ver.: Bol. Soc. Geol. Mex., Tomo IX, No 5

Gibson, J.B.,1936b, Estratigrafía y tectónica de la zona costera del Golfo de México: Bol. Asoc. Mex. Geol. Petrol., v. 5, p. 274-276

Goldhammer, R.K., 1999, Mesozoic sequence stratigraphy and paleogeographic evolution of northeast Mexico: in C. Bartolini, J.L. Wilson, and T.F. Lawton, eds., Mesozoic sedimentary and tectonic history of north-central Mexico: Geological Society of America Special Paper 340, p. 1-58

Goldhammer, R.K., y Johnson, C.A., 2001, Middle Jurassic-Uper Cretaceous Paleogeographic evolution and sequence stratigraphic framework of the northwest Gulf of Mexico rim: in C. Bartolini, T. Buffler, and A. Cantú-Chapa, eds., The western Gulf of Mexico Basin: Tectonics, sedimentary basins and petroleum systems: American Association of Petroleum Geologists Memoir 75, p. 45-81.

González G., R., y Holguín Q., N., 1992, Geology of the source rocks of Mexico: 13th World Petrol. Congr., Proceed., v. XLI, p. 37-50

Grajales-Nishimura, J.M., E. Cedillo-Pardo, C. Rosales-Domínguez, D.J. Morán-Zenteno, W. Alvarez, P. Claeys, J. Ruíz-Morales, J. GarcíaHernández, P. Padilla-Avila, A. Sánchez-Ríos, 2000, Chicxulub impact: The origin of reservoir and seal facies in the southeastern Mexico oil fields: Geology, v. 28, p. 307-310

Guerrero García, J.C., 1975, Contributions to paleomagnetism and RbSr geochronology: Ph.D. Dissertattion, The University of Texas at Dallas, $152 \mathrm{p}$.

Hernández-García, R., 1973, Paleogeografía del Paleozoico de Chiapas, México: Asoc. Mex. Geól. Petrol., v. 25, P73-113

Hess, H.H., Maxwell, J.C., 1963, Caribbean Research Project: Geological Society of America Bull., v. 64, p. 1-6

Hill, R.T., 1902, The geographic and geologic features and their relationship to the mineral products of Mexico: Trans. Amer. Inst. Min. Engrs., v. 32, p. 163-178

Hiller, R., Weber, B., Hetch, L., Ortega G., F., Schaaf, P. y López M., M., 2004, The "Sepultura Unit" - A medium to high grade metasedimentary sequence in the Chiapas Massif, SE Mexico: IV Reunión Nacional de Ciencias de la Tierra, Juriquilla, Qro., Libro de Resúmenes, p. 200

Holguín Q., N., 1985 (1988), Evaluación geoquímica del sureste de México: Bol. Asoc. Mex. Geol. Petrol., v. 37, p. 3-48

Humpris, Jr., C.C., 1979, Salt movement on continental slope, northern Golf of Mexico: American Association of Petroleum Geologists Bull., v. 66, p. $782-798$

Imlay, R.W., 1953, Las Formaciones Jurásicas de México: Bol. Soc. Geol. Mex., T. 16, p. 65 p.

Jacobo A., J., M. Garduño, F. Innocenti, M. Manetti, G. Pascuaré y S. Tonarini, 1992, Datos sobre el vulcanismo geogénico-reciente del Complejo Volcánico de Los Tuxtlas, Edo. De Veracruz, México: Evolución petrológica y geovulcanológica: 11 Convención Geológica Nacional, Veracruz, Libro de Resúmenes, p. 97-98

Jennette, D., T. Wawrzyniec, K. Fouad, D.B. Dunlap, J. Meneses Rocha, F. Grimaldo, R. Muñoz, D. Barrera, C.T. Williams-Rojas, and A. Escamilla Herrera, 2003,Traps and turbidite reservoir characteristics from a complex and evolving tectonic setting, Veracruz Basin, southeastern Mexico: American Association of Petroleum Geologists Bull., V. American Association of Petroleum Geologists Bulletin, v. 87, pp. 1599-1622

Lawton, T. F., F. J. Vega, K. A. Giles, and C. Rosales Domínguez, 2001, Stratigraphy and origin of the La Popa basin, Nuevo Leon and
Coahuila, Mexico, in: C. Bartolini, R. T. Buffler, and A. CantúChapa, eds., Mesozoic and Cenozoic evolution of the western Gulf of Mexico Basin: tectonics, sedimentary basins and petroleum systems: American Association of Petroleum Geologists Memoir 75 , p. $219-240$

Limón-González, M., Cedillo Pardo, E., Quezada Muñetón, J. M., Grajales -Nishimura, J. M., Alvarez, W., Hildebrand, A. R., Sánchez Ríos, M.A., Rosales Dominguez, M. C., and González Casildo, V., 1994, Cretaceous-Tertiary boundary sedimentary breccias from southern Mexico: Normal sedimentary deposits or impact related breccias?: American Association of Petroleum Geologists, Abstracts, v. 3, p. 199

López-Infanzón, M., 1986, Petrología y radiometría de rocas ígneas y metamórficas: Bol. Asoc. Mex. Geól. Petrol., v. 33, p. 59-98

López-Vega, J., 1980, Evaluación económica petrolera del área ComitánPedregal, Estado de Chiapas: Bol. Asoc. Mex. Geol. Petrol., v. 32 , p. $57-77$

Martínez-Castillo, F.J., 2001, Geological study of the Miocene Rodador Field and its exploitation possibilities, Tabasco State, Southeastern Mexico, in Bartolini, C., Buffler, R.T. y Cantú-Chapa, A., (Editores), The Western Gulf of Mexico Basin: Tectonics, Sedimentary Basins, and Petroleum Systems: American Association of Petroleum Geologists Memoir 75

McBirney, A.R., 1963, Geology of the central guatemalan cordillera: Univ. California Publ. Geol. Sci., 38, p. 177-242

Meneses R., J.J., 1991, Tectonic development of the Ixtapa Graben, Chiapas, México: Ph.D. dissertation, The University of Texas at Austin, $308 \mathrm{p}$.

Meneses R., J.J., 2001, Tectonic evolution of the Ixtapa Graben, an example of a strike-slip basin of southeastern Mexico: Implications for regional petroleum systems; in: C. Bartolini, R. T. Buffler, and A. Cantú-Chapa, eds., Mesozoic and Cenozoic evolution of the western Gulf of Mexico Basin: tectonics, sedimentary basins and petroleum systems: American Association of Petroleum Geologists Memoir 75, p. 183-216

Michaud, F., 1987, Stratigraphie et paleogeographie du Mesozoique du Chiapas, sud-est du Mexique: These du Doctorat, Université Paris 6, $301 \mathrm{p}$

Molina-Garza, Roberto S. e Iriondo, Alexander, 2005, La Megacizalla Mojave-Sonora: la hipótesis, la controversia y el estado actual de conocimiento, in, Alaníz-Álvarez y Nieto-Samaniego (Eds.), Grandes Fronteras Tectónicas de México, Sociedad Geológica Mexicana, Vol. Conmemorativo del Centenario, T. LVII, No. 1, p. $1-26$

Morán-Zenteno, Dante J., Martiny, B., Tolson, G., Solís Pichardo, G., Alba Aldave, L., Hernández-Bernal, M. del S., Macías Romo, C., Martínez Serrano, R.G., Schaaf, P., Silva Romo, G., 2000, Geocronología y características geoquímicas de las rocas magmáticas terciarias de la Sierra Madre del Sur: Bol. de la Sociedad Geológica Mexicana, T. LIII, No. 1, p. 27-58

Mossman, R.W., and Viniegra, F., 1976, Complex fault structures in Veracruz Province of Mexico: American Association of Petroleum Geologists Bull., v. 60, p. 379-388

Muehlberger, W.R., 1965, Late Paleozoic movement along the Texas Lineament: New York Acad. Sci. Trans., Ser. 11, 27, 385-392

Muehlberger, W.R. y Ritchie, A.W., 1975, Caribbean-American Plate Boundary in Guatemala and Southern Mexico as seen on Skylab IV orbital photography: Geology, v. 3, p. 232-235

Oñate E., Roberto, 1950, Estudios Geofísicos de la Cuenca de Veracruz: Bol. Asoc. Mex. Geol. Petrol., v. II, No 4, p. 291-298

Pacheco, C. y Barba, M., 1986, El Precámbrico de Chiapas, un terreno estratotectónico: Sociedad Geológica Mexicana, VIII Convención Nacional, Libro Resúmenes, p. 145

Padilla y Sanchez, R.J., 1982, Geologic evolution of the Sierra Madre Oriental between Linares, Concepcion del Oro, Saltillo, and Monterrey, Mexico: The University of Texas at Austin, Ph.D. Dissertation, $217 \mathrm{P}$.

Padilla y Sanchez, R.J., 1986, Post-Paleozoic tectonics of Northeast Mexico and its role In the evolution of the Gulf Of Mexico: Geofisica Internacional, V. 25, No. 1, P. 157-206 
Padilla y Sánchez, R.J., Martínez S., R.G. y Torres R., V., 1995, Carta Tectónica de los Estados Unidos Mexicanos: Edición Conjunta Facultad de Ingeniería, Universidad Nacional Autónoma de MéxicoInstituto Nacional de Estadística, Geografía e Informática, Escala $1: 2,000,000$

Pantoja A.,J., Rincón O., C., Fries, C., Silver, L., Solorio, O., 1974, Contribuciones a la Geocronología de Chiapas: Bol. Asoc. Mex. Geol. Petrol., V. 26, P. 205-223

PEMEX (Petroloes Mexicanos), 2005, Anuario Estadístico, en: www. pemex.com, referencia consultada en abril del 2006

Pindell, J. L., 1985, Alleghenian reconstructions and subsequent evolution of the Gulf of Mexico, Bahamas, and proto-Caribbean: Tectonics, v. 4, p. 1-39

Pindell, J. L., 1993, Regional synopsis of Gulf of Mexico and Caribbean evolution; in: Pindell, J. L., and Perkins, B. F., eds., Mesozoic and early Cenozoic development of the Gulf of Mexico and Caribbean region, A context for hydrocarbon exploration: Gulf Coast Section, Society of Economic Paleontologists and Mineralogists Foundation, 13th Annual Research Conference Proceedings, p. 251-274.

Pindell, J. L., y L. Kennan, 2003, Mexico and Gulf of Mexico, in: Exploration Framework Atlas Series: Volume 4: Tectonic Analysis, Ltd., unpublished non-exclusive commercial exploration atlas in CD-ROM

Prost, G., and M. Aranda, 2001, Tectonics and hydrocarbon systems of the Veracruz Basin, Mexico, in C. Bartolini, T. Buffler, and A. Cantú-Chapa, eds., The western Gulf of Mexico Basin: Tectonics, sedimentary basins and petroleum systems: American Association of Petroleum Geologists Memoir 75, p. 271- 291.

Quezada-Muñetón, J.M., 1984, El Grupo Zacatera del Jurásico MedioCretácico Inferior de la Depresión Istmica, 20 kilómetros al norte de Matías Romero, Oax.: Sociedad Geológica Mexicana, VII Convención Nacional, Memorias, p. 40-59

Quezada Muñetón, J.M., 1987, El Cretácico Medio-Superior-Terciario Inferior en la Sierra de Chiapas: Bol. Asoc. Mex. Geol. Petrol., v. 39 , p. 3-98

Ramírez-Ramírez, C., 1984, Pre-Mesozoic geology of the HuizachalPeregrina Anticlinorium and adjacent parts of eastern Mexico: Ph.D. dissertation, The University of Texas at Austin, $176 \mathrm{p}$.

Ricoy S., U., 1989, Tertiary terrigenous depositional systems of the Mexican Isthmus Basins: Ph.D. Dissertation, The University of Texas at Austin, $145 \mathrm{p}$.

Robin, C., 1982, México, in: R.S. Thorpe (Ed.), Andesites: John Wiley \& Sons, New York, p. 137-147

Ross, M.I., Scotese, C.R., 1988, A hierarchical tectonic model of the Gulf of Mexico and Caribbean Region: Tectonophysics, v. 155, p. $139-168$

Salvador, A., 1987, Late Triassic-Jurassic paleogeography and origin of Gulf of Mexico basin: American Association of Petroleum Geologists Bulletin, v. 71, p. 419-451

Salvador, A., 1991a, Editor, The Gulf of Mexico Basin: Geological Society of America, The Geology of North America, v. J

Salvador, A., 1991b, Triassic-Jurassic, in A. Salvador, ed., The Gulf of Mexico Basin: Geological Society of America, The Geology of North America, v. J, p. 131-180

Salvador, A., 1991c, Origin and development of the Gulf of Mexico Basin, in A. Salvador, ed., The Gulf of Mexico Basin: Geological Society of America, The Geology of North America, v. J, p. 389-444

Sánchez-Montes de Oca, R., 1969, Estratigrafía y paleogeografía del Mesozoico de Chiapas: Seminario sobre exploración petrolera, Instituto Mexicano del Petróleo, México, v. 3, 31 p.

Sánchez-Montes de Oca, R., 1980, Geología petrolera de la Sierra de Chiapas: Bol. Asoc. Mex. Geol. Petrol., v. 31, Nos. 1-2, p. 67-77

Santiago-Acevedo, J. and Mejía Dautt, O., 1980, Giant field in the southeast of Mexico: Gulf Coast Association of Geological Societies Trans., v. 30, p. 1-31

Santiago-Acevedo, J., Carrillo Bravo, J. y Martell Andrade, B., 1984, Geología Petrolera de México, in, D. Marmissolle-Daguerre (Ed.), Evaluación de Formaciones en México, Schlumberger, p. I.1-I36

Sedlock, R. L., Ortega-Gutiérrez, F. y Speed, R. C., 1993, Tectonostratigraphic terranes and tectonic evolution of Mexico: Geological Society of America Special Paper 278, 153 p.

Shearer, H.K., 1938, Developments in south Arkansas and north Louisiana in 1937: American Association of Petroleum Geologists Bull., v. 22, p.719-727

Silver, L. T., and Anderson, T. H., 1974, Possible left-lateral early to middle Mesozoic disruption of the southwestern North American craton margin: Geological Society of America Abstracts with Programs, v. 6, p. 956

Stephan, J.F., Mercier de Lepinay, B., Calais, E., Tardy, M., Beck, C., Carfantan, J.C., 1990, Paleogeodynamic maps of the Caribbean: 14 steps from Lias to Present: Bull. Soc. Geol. France, 8em Ser., v. VI, no. 6, p. 915-919

Villarello, J., 1909, El pozo de petróleo de Dos Bocas: Instituto Geológico de México, Parte 3, p. 5-112

Viniegra O., F., 1950, Breve análisis geológico de la llamada Cuenca de Veracruz: Bol. Asoc. Mex. Geol. Petrol., v. II, No 4, p. 281-290

Viniegra O., Francisco, 1966, Paleogeografía y tectónica del Mesozoico en la Provincia de la Sierra Madre y Macizo de Teziutlán: Bol. Asoc. Mex. Geol. Petrol., v. 18, p. 145-171

Viniegra O., F., 1971, Age and evolution of Salt basins of southeastern México: American Association of Petroleum Geologists Bull., v. 55 , p. $478-494$.

Viniegra O., F., 1981, El gran banco calcáreo yucateco: Revista Ingeniería, $\mathrm{N}^{\circ} 1$, p. $20-44$

Weeks, W.B., 1938, South Arkansas stratigraphy with emphasis on the older coastal plain beds: American Association of Petroleum Geologists Bull, v. 22, p. 953-983

Winker, C.D., y Buffler, R.T., 1988, Paleogeographic Evolution of Early Deep-Water Gulf of Mexico and Margins, Jurassic to Middle Cretaceous (Comanchean): American Association of Petroleum Geologists Bull., v. 72, p. 318-346

Woods, R.D., Salvador, A. y Miles, A.E., 1991, Pre-Triassic, in Salvador, A. (Ed.), The Gulf of Mexico Basin: Geological Society of America, The Geology of North America, Vol. J, p. 109-129

Williams-Rojas, C.T. y Hurley, N.F., 2001, Geologic controls in reservoir performance in Muspac and Catedral gas fields, Southeastern Mexico, in Bartolini, C., Buffler, R.T. y Cantú-Chapa, A., (Editores), The Western Gulf of Mexico Basin: Tectonics, Sedimentary Basins, and Petroleum Systems: American Association of Petroleum Geologists Memoir 75.

Manuscrito recibido: Junio 29, 2005

Manuscrito corregido recibido: Noviembre 16, 2005

Manuscrito aceptado: Noviembre 21, 2006 